\title{
AIRWAY RESPONSIVENESS Standardized challenge testing with pharmacological, physical and sensitizing stimuli in adults
}

\author{
REPORT WORKING PARTY \\ STANDARDIZATION OF LUNG FUNTION TESTS \\ EUROPEAN COMMUNITY FOR STEEL AND COAL
}

\section{OFFICIAL STATEMENT OF THE EUROPEAN RESPIRATORY SOCIETY}

\author{
P.J. Sterk', L.M. Fabbri',Ph.H. Quanjer', D.W. . Cockcroft ${ }^{2}$
} P.M. O'Byrne ${ }^{3}$, S.D. Anderson ${ }^{4}$, E.F. Juniper ${ }^{5}$, J.-L. Malo ${ }^{6}$

\section{CONTENTS}

1 Introduction

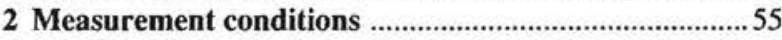

2.1 Indications in clinical diagnosis .................................55

2.2 Contra-indications .........................................................55

2.3 Subject characteristics .................................................55

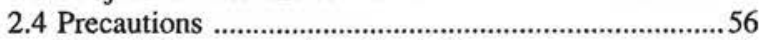

2.4.1 Histamine and methacholine ............................56

2.4.2 Allergens or occupational sensitizers ................56

2.4.3 Other inhalation challenges ................................56

2.5 Choice of the bronchoconstrictor ...................................57

2.6 Lung function measurements ......................................5 57

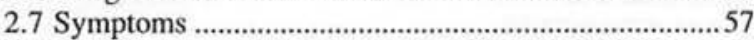

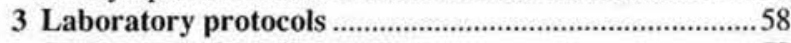

3.1 Pharmacological agents ............................................58

3.1.1 Background ……............................................... 58

3.1.2 Solutions ....................................................... 58

3.1.3 Aerosol generation ….........................................5 58

3.1.4 Tidal breathing method .....................................6 60

3.1.5 Dosimeter method …..........................................60

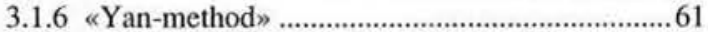

3.1.7 Calculation of the response ................................61

3.1.8 Expression of the response ................................61

3.2 Hypo- and hypertonic aerosols ...................................... 62

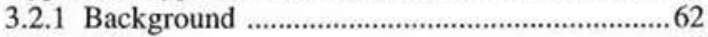

3.2.2 Solutions ………………………...........................62 62

3.2.3 Aerosol generation ….......................................62

3.2.4 Protocol ..............................................................63

3.2.5 Expression of the response ................................ 63

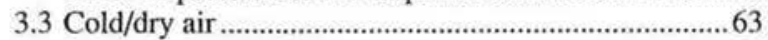

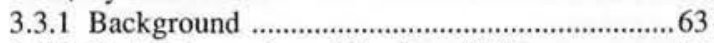

3.3.2 Production and conditioning of air .....................64

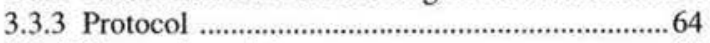

3.3.4 Expression of the response .................................64

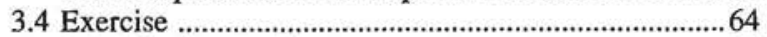

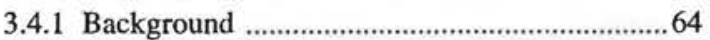

3.4.2 Experimental set-up ..............................................65

3.4.3 Protocol ….......................................................65

'Members Working party

${ }^{2}$ Dept. Medicine, University of Saskatchewan, Saskatoon, Saskatchewan, Canada

${ }^{3}$ Dept. Respiratory Medicine, McMaster University, Hamilton, Ontario, Canada
3.4.4 Expression of the response ..................................66

3.5 Allergen inhalation tests ...............................................6 66

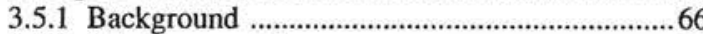

3.5.2 Solutions and dose-range .........................................66

3.5.3 Aerosol generation ...............................................67

3.5.4 Protocol ...........................................................67

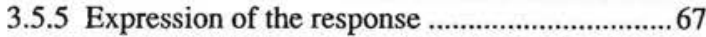

3.6 Occupational sensitizers ................................................6 68

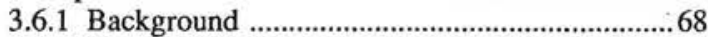

3.6.2 Agents .....................................................................68

3.6.3 Dose delivery ........................................................69

3.6.4 Level and duration of exposure ..........................70

3.6.5 Expression of the response .................................70

3.7 Experimental challenge tests .........................................71

3.7.1 Adenosine 5'-monophosphate (AMP) ...............71

3.7.2 Leukotrienes ....................................................71

3.7.3 Platelet activating factor (PAF) ........................... 71

3.7.4 Bradykinin ..................................................... 71

3.7.5 $\mathrm{SO}_{2}$ and sodium metabisulphite .........................71

3.7.6 Tachykinins ............................ 72

3.7.7 Propranolol .......................................................... 72

4 Analysis and interpretation ...........................................72

4.1 Dose-response curves: indices and terminology .........72

4.2 Time-response curves .....................................................

4.3 Reproducibility .............................................................. 73

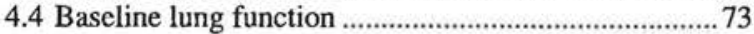

4.5 Clinical relevance of the various challenges ................73

4.6 Applications in research ................................................74

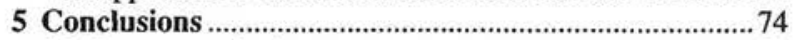

5.1 Recommendations .........................................................

5.1.1 General ...............................................................75

5.1.2 Clinical usage .................................................. 75

5.1.3 Materials and methods .......................................75

5.1.4 Analysis and interpretation .................................75

5.2 Remaining questions .................................................76

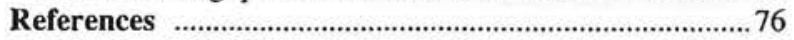

${ }^{4}$ Dept. Thoracic Medicine, Royal Prince Alfred Hospital, Camperdown, Australia

${ }^{5}$ Dept. Clinical Epidemiology and Biostatisitics, McMaster University, Hamilton, Ontario, Canada.

${ }^{6}$ Dept. Chest Medicine, Hôpital du Sacré-Coeur,Montreal, Quebec, Canada 


\section{Introduction}

Asthma and chronic obstructive pulmonary disease (COPD, also called chronic airflow limitation (CAL)) are the most frequent diagnoses in patients with intrathoracic airways obstruction [1]. Often these patients show a spontaneous variability in the degree of airways obstruction, which can be documented by serial lung function measurements. Large variability in the degree of airways obstruction is indicative of an increased susceptibility of the patient to environmental stimuli that cause acute airway narrowing. Knowledge of the potential severity of these episodes of acute airways obstruction is of clinical interest. Therefore, several quantitative measures of the response of the airways to bronchoconstrictors in vivo have been advocated over the past two decades. The objective of the present guidelines is to address the methodological issues of the various available techniques, and to provide up-to-date international guidelines on standardization. The present recommendations might not represent the potentially best methodologies. However, they do represent the currently validated techniques, by which interchangeable results can be obtained among laboratories.

Variable airways obstruction can be mimicked in the laboratory by challenge tests with bronchoconstrictive stimuli (fig. 1) [2]. This enables one to measure the degree of the so-called «airway responsiveness» of the subject to a particular agent. Since the bronchoconstrictive response varies from one stimulus to another, one needs to specify the challenging agent. Therefore, the term «nonspecific» airway responsiveness should be abandoned.

Airway hyperresponsiveness refers to an exaggerated response to the bronchoconstrictor. This is reflected by an increased sensitivity to the stimulus, which is usually accompanied by an excessive severity of the induced obstructive response [3]. The term «hyperresponsiveness» is recommended as a general description of the phenomenon. «Hypersensitivity» and «hyperreactivity» specifically refer to a leftward shift and an increase in slope, respectively, of the dose-response curve obtained during a challenge test (fig. 1) (see § 4.1) [2, 3]. Because most investigators assume that the bronchi are the major component in these responses, the terms «airway hyperresponsiveness» and «bronchial hyperresponsiveness» are used interchangeably.

The mechanisms underlying airway hyperresponsiveness have not been fully clarified [4]. Both genetic predisposition (associated with atopy) and environmental factors (e.g. virus infections) could be involved in its pathogensis [5]. Airway hyperresponsiveness seems to be a composite physiological disorder, determined by a heterogeneous mechanism in asthma [6] as well as in COPD [7]. It appears to be associated with inflammatory disorders in the airways in both disease entities. In asthma, the mucosal inflammation comprises epithelial desquamation, thickening of the sub-epithelial reticular layer, microvascular congestion, plasma exudate and oedema, smooth muscle hyperplasia and hypertrophy, and (sub)mucosal infiltration with mast cells and activated lymphocytes and

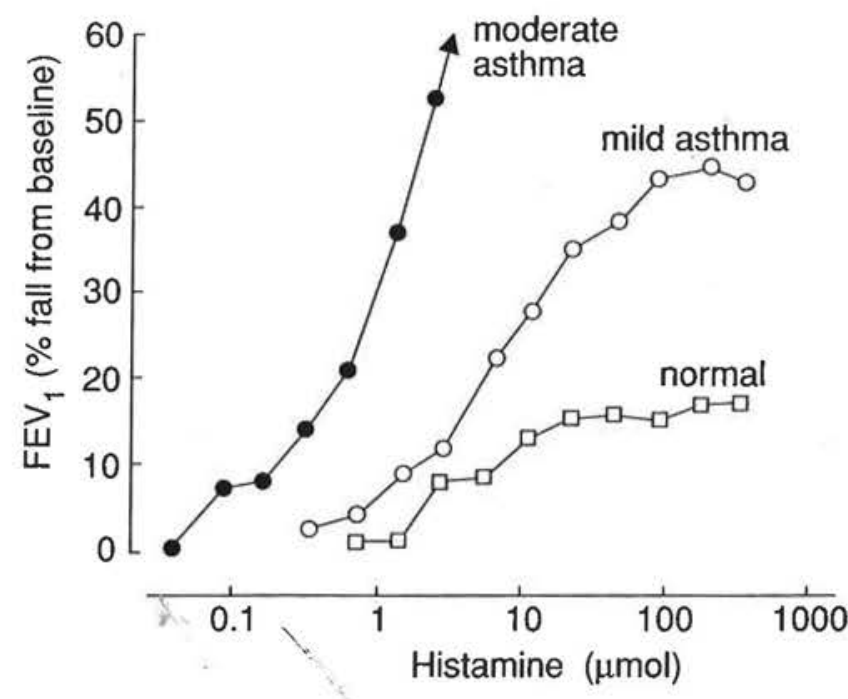

Fig. 1. - Dose-response curves to inhaled methacholine using the dosimeter method in 3 subjects. Airway hyperresponsiveness in asthma is characterised by a leftward shift of the curve (hypersensitivity), a steeper slope (hyperreactivity), and an increase in maximal response (excessive airway narrowing). Modified from de Pee $e t$ al. [243] with permission.

eosinophils $[8,9]$. In COPD, the inflammatory disorders differ between the various subtypes of the disease: chronic bronchitis, peripheral airways disease or emphysema $[9,10]$. (Activated) T-lymphocytes and macrophages seem to be the predominant infiltrating cells in COPD, without concomitant sub-basement membrane thickening [11, 12]. Several of the above inflammatory abnormalities are correlated with the results of inhalation challenge tests [38]. Therefore, the degree of airway hyperresponsiveness may indirectly reflect the severity of the disease process in the airways in asthma and COPD. This has been extensively reviewed elsewhere [13].

Inhalation challenge procedures are currently applied in research studies as well as in clinical practice. Both circumstances need descriptions of specific measurement conditions, such as the selection of subjects, the choice of the stimulus, the delivery of the stimulus, the method of measurement of bronchoconstriction, and technical or medical precautions. In addition, it has become evident that challenge tests with each of the various bronchoconstrictor stimuli require distinct laboratory protocols [14]. Therefore, the protocols for the most commonly used challenges with pharmacological agents (histamine, methacholine), physical stimuli (non-isotonic aerosols, cold/dry air, exercise), and sensitizing agents (allergens, occupational sensitizers) will be separately addressed. Finally, attention will be paid to the analysis of the data and the interpretation of the results in the clinical setting and in research studies. It needs to be emphasized that, despite a broad consensus on most of these methodological issues, there are still a number of unsolved dilemma's regarding the standardization of inhalation challenge tests. These are addressed at the end of this report. Since the measurement of airway responsiveness in infants and children is an issue by itself, the present document is focused on adults with only incidental reference to children. 


\subsection{Indications in clinical diagnosis}

Inhalation challenge tests are being used in research studies as well as in clinical practice. The indications for performing inhalation challenge tests in research depend on the hypothesis and objective of the study. The tests are particularly important in follow-up studies in patients with asthma, for which guidelines have been provided [15].

Challenge tests can potentially play a role in daily practice in the clinical diagnosis of patients with variable airways obstruction $(\S 4.5)[16,17]$. From clinical and epidemiological studies it appears that airway responsiveness measurements supply valuable information about airways disease, in addition to that from symptoms, spirometry and diurnal peak flow variation $[18,19]$. The tests document the potential of variable airways obstruction, and may be useful in those patients in whom this can not be recorded in another way. Does this imply that the tests are useful in diagnostic procedures? Regarding the diagnosis of asthma, the usefulness of pharmacological challenges in clinical practice differs from that in the epidemiological setting [20]. It strongly depends on the prevalence of asthma in the population under investigation $[21,22]$. The pharmacological tests are particularly suitable for the exclusion of asthma in the clinic $[20,21,23$, 24], because of the high sensitivity (= number of asthmatic subjects with a positive test per total number of asthmatic subjects) and high negative predictive value (= number of non-asthmatic subjects with a negative test per total number of subjects with a negative test). However, the tests are less useful to confirm the diagnosis, particularly in epidemiological studies [20,21,23,24], due to their moderate specificity ( $=$ number of non-asthmatic subjects with a negative test per total number of non-asthmatic subjects) and relatively low positive predictive value (= number of asthmatic subjects with a positive test per total number of subjects with a positive test). Careful selection of multiple cut-off values can optimize the positive and negative predictive values of the test, even though this introduces a considerable intermediate «grey» area of inconclusive test results [24]. Therefore, the indication of challenge tests in diagnostic procedures of asthma seems to be limited to those patients with typical symptoms without otherwise documented variable airways obstruction $[21,22]$. Since airway hyperresponsiveness is also associated with COPD, a positive test result can not be used in the differential diagnosis with asthma [18]. Therefore, in the presence of airways obstruction the tests are hardly indicated. So far there are no challenging agents that allow a clear distinction between asthma and COPD [25].

Serial measurements of airway responsiveness seem to be useful during clinical follow-up, in order to monitor any aggravation of responsiveness following exposure to sensitizing agents, and to document improvement after therapeutic interventions ( $\S 4.5)[20,26]$. Even though within-subject changes in airway responsiveness to histamine do not consistently reflect the clinical expression of asthma [27], the measurements may indirectly provide additional information above FEV, about changes in the inflammatory state of the airways and the likelihood of obstruction if an appropriate stimulus is encountered [28]. In addition, the degree of airway hyperresponsiveness reflects the need for medication [16]. However, it needs to be emphasized that the current international consensus on asthma therapy does not recommend hyperresponsiveness to be used as a guide for the level of treatment [17].

Finally, it can be postulated that the level of airway responsiveness has a prognostic value in asthma [26]. Although there is some controversy on this in longitudinal epidemiological studies [29, 30], airway responsiveness appears to be of prognostic significance in prospective clinical studies in children [31] as well as in adults [32]. If these findings can be confirmed in other studies, the prognostic value might become one of the major indications of challenge tests in research and clinical practice.

\subsection{Contra-indications}

Challenge tests should always be done at the discretion of a physician. There are no data in support of any strict contra-indication of doing an inhalation challenge tests. The current standardized procedures have been shown to be safe during numerous clinical studies (see $\S 2.4$ ). Nevertheless, the following absolute contra-indications are recommended:

a severe airways obstruction at baseline $\left(\mathrm{FEV}_{1}<1.2 l\right.$ in adults),

b recent myocardial infarction ( $<3$ months),

c recent cerebral vạscular accident ( $<3$ months),

d known arterial aneurysmata,

e inability to understand the procedures and the implications of a challenge test.

Relative contra-indications are the following:

a spirometry-induced airways obstruction,

b moderate to severe airways obstruction (e.g. $\mathrm{FEV}_{1}<$ predicted value minus $3 \cdot S D$ of the predicted value: predicted $\mathrm{FEV}_{1}$ minus $1.5 \mathrm{l}$ in males and predicted FEV, minus $1.2 l$ in females [33],

c recent upper respiratory tract infection $(<2 \mathrm{wks})$,

d during exacerbations of asthma,

e hypertension,

f pregnancy,

$\mathrm{g}$ epilepsia requiring drug treatment.

\subsection{Subject characteristics}

In addition to the contra-indications mentioned above ( $\S$ 2.2), several patient characteristics need attention prior to inhalation challenge testing. Document any noticeable recent relevant allergen or sensitizer exposure. Record all drug therapy, including the last dose and the time it was taken. Oral and inhaled bronchodilators ( $\beta$-adrenergic agents, ipratropium bromide, theophyllines) should be withheld for their duration of action. This also holds for 
antihistamines (except for methacholine challenge), that should be stopped 4 days prior to the test ( $6 \mathrm{wks}$ for asteizole if taken daily for at least one wk [34]). Sodium cromoglycate, nedocromil, and corticosteroids may have acute and long-term effects on airway responsiveness [35]. Even though there is a small acute effect of e.g. steroids on histamine responsiveness [36], these so-called antiinflammatory drugs are usually not withheld prior to histamine or methacholine challenge. Sodium cromoglycate and nedocromil have an acute protective effect against most non-pharmacological challenges [35, 37], whilst inhaled steroids particularly inhibit the late asthmatic response following allergens or occupational sensitizers [38]. Therefore, these drugs are usually withheld before non-pharmacological challenges. Finally, sodium cromoglycate, nedocromil, and inhaled steroids do have long-term attenuating effects on airway responsiveness: which need to be taken into account when interpreting the results [35, 37].

Besides medication usage, baseline lung function, the response to diluent, and the degree of atopy (allergen) are relevant for selecting the starting dose of the challenge (see below). The effect of prior smoking or usage of caffeine-containing beverages on the challenge tests is probably small but is still controversial. Before the challenge, the technician needs to explain and demonstrate the test to the patient.

\subsection{Precautions}

The precautions that are required when carrying out inhalation challenge tests vary between the different types of stimuli. In general, the safety of standardized histamine and methacholine tests is recognized all over the world. Therefore, the safety requirements for these tests are relatively simple. In contrast, tests with sensitizing agents such as allergens or occupational sensitizers, need extensive precautions and patient-monitoring including the night and day following the experiment. As the experience with the physical tests (exercise, cold air, hypo- and hypertonic aerosols) and with any other pharmacological tests than histamine or methacholine is still relatively limited, the safety requirements for these tests should also be stringent. In case of any doubt, similar precautions as those for allergen challenges should be taken (see $\S$ 2.4.3). The precautions for challenge tests include: laboratory materials, personnel training, and written safety protocols.

\subsubsection{Histamine and methacholine}

Challenge tests with histamine and methacholine, performed in a carefully standardized manner, are safe. Therefore, the precautions during these tests are those that are recommended in general in any clinical lung function laboratory. This includes oxygen and bronchodilators [39]. Personnel should be trained in the management of acute severe asthma $[17,39]$.

If the test is performed in the context of epidemiological surveys, it can be carried out even if a physician is not present provided that:
1 a standardized protocol is used and the starting dose should be low;

2 baseline $\mathrm{FEV}_{1}$ is $\geq$ predicted value minus $3 \cdot \mathrm{SD}$ of the predicted value $[33](\S 2.2)$ and $\geq 2 l$;

3 no significant bronchoconstriction occurs after the nebulisation of diluent;

4 a trained and experienced technician performs the test;

5 oxygen and a $\beta_{2}$-adrenergical agent can be readily used;

6 the responsible physician or a community physician informed of the protocol and qualified to manage bronchoconstriction can rapidly (within $10 \mathrm{~min}$ ) see the subject in case of emergency.

If the test is performed in the hospital, a doctor experienced in challenge tests should be present in the hospital and readily available if needed, as criteria no. 2 and 3 listed above might not be fulfilled.

Under all circumstances, the patient must not be left unattended at any time. The patient should be instructed to discontinue inhalation if symptoms become troublesome. At the end of the test the patient should only leave the testing area after his/her bronchoconstriction has adequately improved, either spontaneously or by inhaled bronchodilator (towards $\mathrm{FEV}_{1}$ values $>90 \%$ of baseline) [40]. The patient should also receive proper instructions in case of relapse of bronchoconstriction during the first $24 \mathrm{~h}$ after the test.

\subsubsection{Allergens or occupational sensitizers}

If challenges with allergens or occupational sensitizers are carried out, in addition to the above ( $\$ 2.4 .1$ ), cardiopulmonary resuscitation equipment must be available in the room, together with ready to use oxygen, inhaled and intravenous bronchodilators, intravenous anti-histamines, intravenous steroids and adrenaline (see $\S 3.5$ and $\S 3.6$ ) $[17,39]$. The inhaled doses must be carefully standardized according to the present recommendations ( $\S 3.5 .2-$ $3.5 .4, \S 3.6 .2-3.6 .4)$. The tests can only be performed by a specifically trained technician, and a doctor, experienced in this type of challenge and in acute severe asthma, must be present in the room during the challenge. After the challenge, the doctor should be at close call in the laboratory. The patient is monitored in the laboratory for at least $7 \mathrm{~h}$, and lung function (e.g. PEF) should be measured repetitively during the first $24 \mathrm{~h}$. Severe airways obstruction should be treated adequately $[17,39]$.

\subsubsection{Other inhalation challenges}

The very stringent precautions identified in $\S 2.4 .2$ are also required for many other inhalation challenges, particularly those tests that have not been fully standardized. This includes tests with any other pharmacological or sensitizing agents. With regard to the physical challenges, there is general consensus that standardized exercise tests are safe (see § 3.4). However, the experience with other physical tests is still relatively limited. Therefore, it is recommended that the safety equipment should be similar as that for allergen challenge, and that a doctor, experienced in this type of challenge, is readily available. If a 
late response can be expected, lung function should be monitored as after allergen challenge ( $\$ 2.4 .2)$. Alternatively, if bronchoconstriction is adequately improved (see $\S 2.4 .1$ ) the observation period in the laboratory following these challenges may be shorter than for allergens, according to the recommendations for histamine and methacholine.

\subsection{Choice of the bronchoconstrictor}

Acute airways obstruction can arise from smooth muscle contraction either with or without inflammatory changes in the airway wall. These inflammatory changes include: hyperaemia, plasma exudate, oedema, or hypersecretion, which by themselves may not cause serious airway narrowing, but in combination with smooth muscle sontraction will lead to severe, acute obstruction [41, 42]. These bronchoconstrictor mechanisms are involved to a various extent during different types of challenge tests $[14,35,43]$. Some bronchoconstrictors act directly and predominantly on airway smooth muscle itself (e.g. methacholine, histamine), whereas other stimuli depend on the involvement of cellular or neurogenic mechanisms, indirectly leading to smooth muscle contraction and possibly to inflammatory changes in the airway wall (e.g. non-isotonic aerosols, cold/dry air, exercise) [43]. The inflammatory mechanisms predominate after challenge with sensitizing agents, particularly during late asthmatic reactions (e.g. allergens, occupational sensitizers) [38]. In addition, these challenges by themselves can also cause temporary increase in airway responsiveness to other, nonsensitizing stimuli $[14,35]$. Therefore, the results of the various challenge tests are only weakly correlated and thereby not interchangeable, each implicitly providing different information. The discordance between the tests may also arise from the distinct ways of expressing the response (e.g. obtained from dose-response or timeresponse curves) [44]. This warrants further pathophysiological and clinical studies, particularly during follow-up of therapeutical interventions [44].

The choice of the bronchoconstrictor stimulus to be used depends on pathophysiological, methodological, and clinical criteria $[14,35]$. Pharmacological challenges with histamine or methacholine have best been standardized and validated in patients with asthma or COPD. It can be argued that physical challenges are better at mimicking naturally encountered bronchoconstrictor stimuli, thereby having more impact for clinical problems. However, these tests have less stringently been standardized. They also have a couple of drawbacks, such as the relatively small range of the doses that can be administered, and the still limited experience with these tests in clinical epidemiology. Challenge tests with sensitizing agents are hardly ever needed in clinical practice (except in the case of agents encountered in the workplace) ( $\$ 3.5 .3$ and 4.5), but they are extremely useful in pathophysiological studies. In research studies the choice of the challenge depends on the pathophysiological pathway under investigation (§ 3.7).

\subsection{Lung function measurements}

Airways obstruction can be documented in a number of ways [33]. Two types of measurements need to be distinguished: those preceded by a deep inspiration to total lung capacity (FVC, $\mathrm{FEV}_{1}$, peak expiratory flow, and maximal expiratory flow-volume curves), and those without a deep inspiration (airways resistance or conductance, and partial expiratory flow-volume curves) [2]. Since a deep inspiration can either cause transient bronchodilatation or bronchoconstriction [33,45], this distinction is highly relevant during challenge procedures, particularly in research.

Although the various methods of lung function assessment highlight different aspects of lung mechanics, their behaviour during challenge tests in clinical practice is very similar [46]. Among the measurements including a deep inspiration, the $\mathrm{FEV}_{1}$ is first choice. There is no clear benefit from ușing other measurements obtained from the maximal expiratory flow-volume curve [2]. The measurement of $\mathrm{FEV}_{1}$ is well standardized, as is extensively discussed elsewhere in this issue [33]. Even though the recording of FEV, implicitly affects the degree of obstruction by the preceding deep inspiration, its use in serial measurements of airway responsiveness leads to the most reproducible results [46]. The forced vital capacity (FVC) may provide additional information to $\mathrm{FEV}_{1}$ during challenge tests, particularly on airway closure, which may predict the maximal response to bronchoconstrictors [47]. However, repetitive FVC measurements are exhausting for the patient and, therefore, they are not recommended for routine use.

Lung function tests without a deep inspiration, such as specific airways conductance [48] or partial flow-volume curves [49], are more sensitive to small changes in bronchoconstriction than $\mathrm{FEV}_{1}$ [46]. This makes them more suitable for research studies in normal subjects, in whom the response to bronchoconstrictors is limited [50]. However, the reproducibility of airway responsiveness measurements with these methods is substantially less than with $\mathrm{FEV}_{1}$ [46], so that the latter is recommended in clinical practice and epidemiological studies.

\subsection{Symptoms}

Even though bronchoconstriction can best be documented by lung function assessment, symptoms of breathlessness during the challenge may provide additional information that is clinically or pathophysiologically relevant. The best validated method for measuring the breathlessness that is perceived during exertion is the Borg category scale [51], which has also been applied to histamine and allergen challenge testing [52, 53]. A promising alternative for pharmacological challenge testing might be the visual analogue scale (VAS) for breathlessness [54]. However, further validation of these techniques during various challenge tests will be required. Therefore, at this stage they cannot be recommended as outcome variables of airway responsiveness measurements. 


\section{Laboratory protocols}

\subsection{Pharmacological agents}

\subsubsection{Background}

Pharmacological challenges with aerosolized solutions of carbachol [55] or histamine $[56,57]$ were introduced on both sides of the Atlantic about half a century ago. The procedures were further developed by DE VRIES $e t$ al. [58] and OREHEK [59], and subsequent worldwide application of histamine and methacholine inhalation challenge tests was based on the work of HaRGREAVE et al. [60]. Currently, these pharmacological challenges are the first choice for airway responsiveness measurements in clinical practice as well as in research $(\S 2)$.

Histamine is one of the major inflammatory mediators involved in asthma, producing airways obstruction by smooth muscle contraction, and to some extent by increased microvascular permeability and/or stimulation of (non)cholinergic activity [61]. Carbachol and methacholine are synthetic muscarinic agonists that are more stable than acetylcholine itself and not degradable by cholinesterase [59]. Even though carbachol challenges have been used in asthma [62], most current experience exists for methacholine [60]. The solubility of methacholine allows administration of higher doses than with histamine, without side effects [50]. This may be particularly useful in epidemiological studies. Remarkably, histamine and methacholine provide concordant results (comparable PC or PD values) although they are not fully interchangeable (§ 3.1.8).

\subsubsection{Solutions}

HISTAMINE ACID PHOSPHATE (HISTAMINE DI-PHOSPHATE)

Standardized solutions of histamine are usually made from histamine di-phosphate powder (HDP, molecular weight: 307) and phosphate-buffered saline (PBS). Phosphatebuffered saline is used as the diluent because, at higher histamine concentrations, unbuffered solutions become sufficiently acid to alter the response of the airways [63]. PBS and histamine di-phosphate solutions need to be prepared in a carefully standardized manner, particularly paying attention to the molecular water content of the various salts (e.g. $\left.\mathrm{HDP}_{1} 1 \mathrm{H}_{2} \mathrm{O}\right)$. Recently, detailed recommendations on this have been supplied (table 1) [64].

To make a solution of $32 \mathrm{mg} \cdot \mathrm{ml}^{-1}$ histamine: weigh $32.00 \mathrm{~g} \mathrm{HDP}$ (or $33.88 \mathrm{~g} \mathrm{HDP} .1 \mathrm{H}_{2} \mathrm{O}$ ) and add $1000 \mathrm{ml}$ of sterile PBS. Filter through a $0.22 \mu \mathrm{m}$ filter, put into a sterile vial and autoclave. Histamine di-phosphate does not dissolve easily in phosphate-buffered saline and the higher concentrations may precipitate out when stored at $4^{\circ} \mathrm{C}$. These solutions should be shaken well before use.

METHACHOLINE (ACETYL- $\beta$-METHYL CHOLINE CHLORIDE) The $\mathrm{pH}$ of methacholine solutions is stable and a buffered diluent is not needed. Normal saline should be used as the diluent because solutions made up with phosphate buffered saline have shown chemical instability over a period of three months [65]. Methacholine powder is highly hygroscopic; it must be stored in a dry container in a freezer and handled very carefully to ensure accurate dry concentrations [66]. At higher concentrations, methacholine becomes more viscous such that by $256 \mathrm{mg} \cdot \mathrm{ml}^{-1}$, nebulizer output for a given flow is significantly reduced and adjustments need to be made. If methacholine chloride is not available, methacholine bromide can be used instead. Both methacholine salts have been shown to have equal biological potency, at least when expressed on a molar-base $(1 \mathrm{~mol}$ methacholine chloride $=195.4$ $\mathrm{g}, 1 \mathrm{~mol}$ methacholine bromide $=239.9 \mathrm{~g}$ ) [67].

To prepare a solution of $100 \mathrm{mg} \cdot \mathrm{ml}^{-1}$ methacholine, -weigh out $5 \mathrm{~g}$ methacholine powder and dissolve in $\mathbf{4 5}$ ${ }^{\mathrm{ml}} \mathrm{normal}$ saline. Filter through a $0.22 \mu \mathrm{m}$ filter and put into a sterile vial.

Table 1. - Preparation of histamine solution.

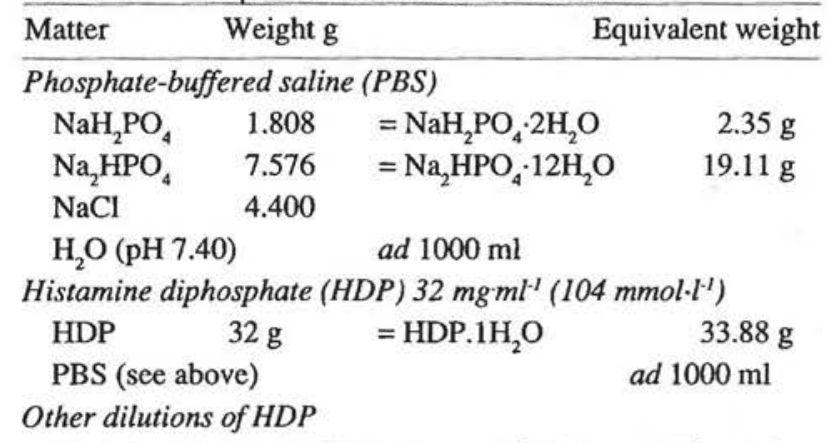

Made by diluting the HDP $32 \mathrm{mgml}^{-1}\left(104 \mathrm{mmol} l^{-1}\right)$ solution with PBS

Remarks: Sterilization: $20 \mathrm{~min}$ at $120^{\circ} \mathrm{C}$. No preservative added. Stored in dark place at $4^{\circ} \mathrm{C}$

according to BRAND et al. [64].

StORAGE OF TEST SOLUTIONS

Histamine and methacholine solutions should be stored in the dark at $4^{\circ} \mathrm{C}$. At this temperature, both are stable for at least three months [65, 68-71]. However, bacterial contamination enhances degradation rapidly [70]. Therefore, single use ampoules might be preferable. Since temperature affects nebulizer output, solutions should be allowed to equilibrate to room temperature (approximately $30 \mathrm{~min}$ ) before use [72].

\subsubsection{Aerosol generation}

Airway responsiveness is defined as the response of the airways to a provoking agent. It is essential for a reliable assessment of responsiveness that both the dose of the provoking agent and the response are measured accurately. Unless both are carefully standardized, results are unreliable and cannot be related to previously established reference values [60]. It is of overriding importance that the aerosol generation for one type of challenge is consistent between and within subjects, so that the same dose is delivered in an identical way on different occasions. 
The current standardization of the dose refers to the amount of provocative agent administered to the mouth. The factors that determine the deposition of aerosols in the airways are [73]: the number and size of the droplets delivered to the mouth, air temperature and relative humidity, airways geometry and breathing pattern. Due to oropharyngeal deposition the actual dose that enters the lungs can only be estimated.

The doses of aerosol for the three most commonly used histamine/methacholine test procedures, described below, are generated by jet nebulizers. In this section we examine variables that need to be standardized to ensure that the dose is accurate [74]. These methods are theoretically suitable for adults as well as for children. However, one is reminded that with the tidal breathing and dosimeter method children are inhaling the same dose as adults [75]. There is evidence that for similar doses, the response to histamine and methacholine may be greater in children that in adults [75]. Not only should this be taken into consideration when selecting starting doses for children, but also when interpreting the results. To date it is unclear as to whether the dose in children should be sizecorrected [75].

\section{NEBULIZER OUTPUT}

As the driving pressure and the flow rate of compressed air to a nebulizer increases, the aerosol output increases and the resultant increased dose provokes greater airway narrowing. Therefore, all nebulizers must be calibrated to operate at a known output. The calibration needs to be performed under exactly the same conditions as those under which the system is used during a challenge test.

First, any extra port or vent of the nebulizer must be closed (except for in the "Yan-method» where the vent is open; see $\S 3.1 .6$ ). The driving pressure of the compressed air upstream of the flowmeter should be about $344 \mathrm{kPa}$ (50 p.s.i.) for the tidal breathing method and about $138 \mathrm{kPa}(20$ p.s.i.) for the dosimeter method. Then the nebulizer should be adequately filled with liquid, preferably $3 \mathrm{ml}$, or less if an adequate small reservoir is used [76]. The simplest calibration method is to measure weight loss from the nebulizer at various airflows as indicated by a pressure compensated flowmeter [74]. Weight loss (y-axis) is plotted against airflow (x-axis), and the correct airflow is chosen by linear interpolation at the desired weight loss. For the bolus methods (dosimeter and Yan method) the nebulizer weight loss per actuation is used to calculate the cumulative dose for estimation of the $\mathrm{PD}_{20}$ (see $\S 3.1 .5$ and 3.1.6). For the tidal breathing method, the results are expressed in terms of concentration $\left(\mathrm{PC}_{20}\right)$, and, therefore, nebulizers are adjusted to give a standardized output ( $\$ 3.1 .4$ ). The actual output is regularly checked at the calibrated value of airflow. This is adequate for most clinical and research purposes. However, weighing makes no allowance for evaporation of water during nebulization. By using more sophisticated equipment it appears that solute output is not fully proportional to weight loss $[74,77]$. Therefore, some research studies require more precise methods of measuring nebulizer output.
Nebulizer output varies considerably between different brands of nebulizers and between specimens of the same brand [74]. However, provided there is adequate cleaning, nebulizer output is highly reproducible for individual nebulizers, even after long-term heavy use [78]. Nevertheless, regular checking of nebulizer output is recommended.

\section{PARTICLE SIZE}

The majority of jet nebulizers generate heterodisperse droplets with a mass median aerodynamic diameter (MMAD) of 1 to $4 \mu \mathrm{m}$ [74]. Variation within this range has little effect on the response [79]. It is wise to check the particle size of new nebulizers as there are occasional rogues, but further calibration is rarely needed. Particle size should be expressed in MMAD with the accompanying GSD (geometric standard deviation), and not in mean size or size range.

\section{APPARATUS BETWEEN NEBULIZER AND MOUTH}

Aerosols evaporate, impact or deposit in apparatus placed between the nebulizer and mouth. In general, the distance between the nebulizer and the mouth should be kept to a minimum. Modifications of the face mask or the mouthpiece, tubing, and valve box may seriously affect the dose delivered at the mouth (fig. 2) [80].

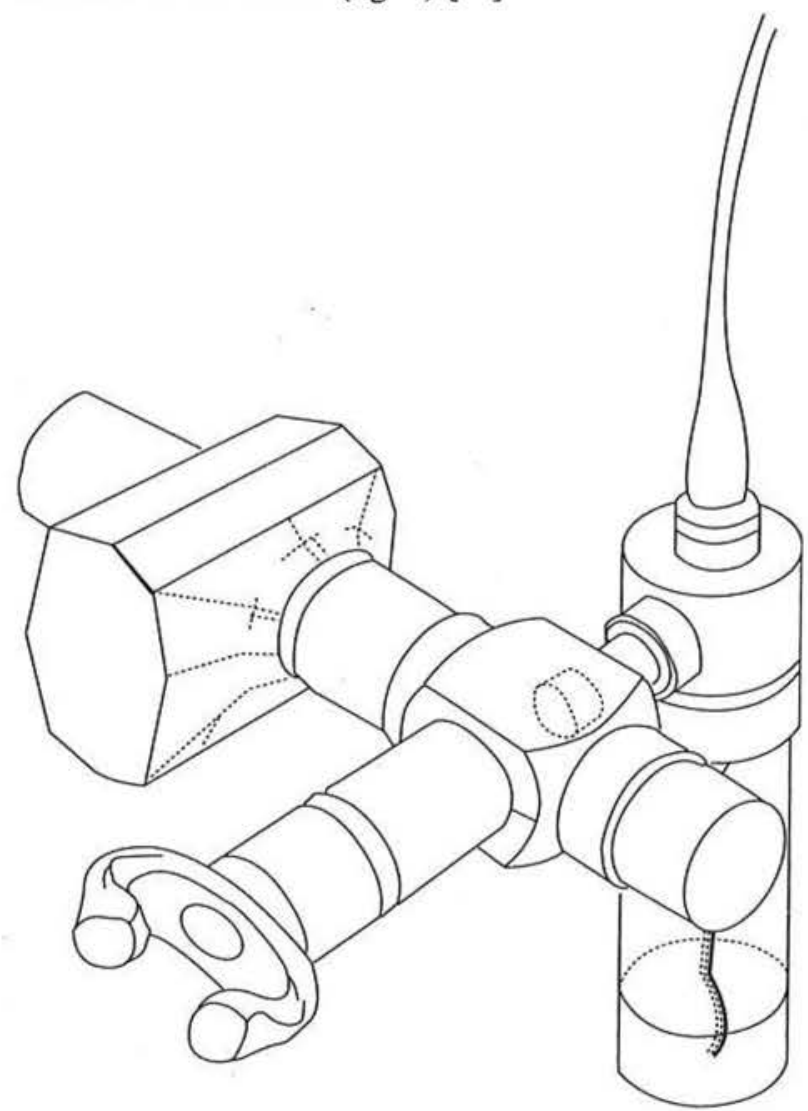

Fig. 2. - Experimental set-up of a jet nebulizer connected to the central chamber of an in- and expiratory three-way valve box with an expiratory aerosol filter. The subject is connected to the mouthpiece. See tidal breathing method $(\$ 3.1 .4)$. Modified from JUNIPER et al. [84], with permission. 


\section{TEMPERATURE AND EVAPORATION}

As compressed air passes through jet nebulizers, significant evaporation occurs and test solutions become colder and more concentrated. After $2 \mathrm{~min}$ of nebulization, the concentration increases by $10 \%$ [81]. Nebulizer output also decreases with cooling (to about $10^{\circ} \mathrm{C}$ ) [72]. To standardize for both these effects, test solutions should be discarded after use and the patients should not be allowed to clasp the nebulizer vial in a warm hand.

\subsubsection{Tidal breathing method [82-84]}

Aerosols of histamine/methacholine are generated by a validated jet nebulizer with MMAD between 1 and $4 \mu \mathrm{m}$, and calibrated to give an output as estimated by weight loss of $0.13 \mathrm{ml} \cdot \mathrm{min}^{-1}$. Aerosols are delivered either through a face mask, held loosely against the face, or through a Hans Rudolph valve box with a mouthpiece [85]. The latter system allows absorption of the expirate in a low resistance aerosol filter attached to the expiratory port of the valve box (fig. 2). Each aerosol is inhaled by quiet tidal breathing at spontaneous frequency through the mouth for $2 \mathrm{~min}$, using a nose clip. The first aerosol inhaled is the diluent and this is followed at $5 \mathrm{~min}$ intervals by doubling concentrations of histamine or methacholine from $0.03-32 \mathrm{mg} \cdot \mathrm{ml}^{-1}$ (or higher concentrations if necessary in research). The FEV is measured before the test and at 30 and $90 \mathrm{~s}$ after each inhalation, the lowest technically satisfactory [33] recording will be used in the analysis. The lowest value reflects maximal bronchoconstriction at a certain dose. It has been chosen in order to take into account slight variations in the time course of bronchoconstriction induced by the agents [86], and because deep inspirations may remove bronchoconstriction [45]. The test is stopped when the FEV, has fallen by $20 \%$ or more from baseline. The results are expressed as the concentration of methacholine/histamine causing a $20 \%$ fall in $\mathrm{FEV}_{1}\left(\mathrm{PC}_{20}\right)$ ( $\$ 3.1 .7$ and 3.1.8). The reproducibility of the test is described in $\S 4.3$.

To shorten the test procedure, low concentrations may be omitted in some patients. However, it should be emphasized that this can only be recommended when the administrator of the test has extensive experience. The starting concentration is calculated from the baseline $\mathrm{FEV}_{1}$, the response to diluent, and current medication usage $[84,87](\S 2.3)$ in the following way:

$1 \mathrm{FEV}_{1} / \mathrm{VC}>80 \%$ and $\mathrm{FEV}_{1}>70 \%$ predicted and $\mathrm{FEV}_{\text {, falls }}<10 \%$ after the diluent inhalation and the patient's symptoms are well controlled, use starting concentrations between 0.125 and $2.0 \mathrm{mg} \cdot \mathrm{ml}^{-1}$, depending on the medication being taken:

$\begin{array}{lr}\text { Medication } & \text { Starting } \\ \text { Inhaled or ingested corticosteroids } & 0.125 \mathrm{mg} \cdot \mathrm{ml}^{-1} \\ \text { Daily bronchodilators } & 0.25 \mathrm{mg} \cdot \mathrm{ml}^{-1} \\ \text { Occasional bronchodilators (< once/day) } & 1.0 \mathrm{mg} \cdot \mathrm{ml}^{-1} \\ \text { No medication } & 2.0 \mathrm{mg} \cdot \mathrm{ml}^{-1}\end{array}$

$2 \mathrm{FEV}_{1} / \mathrm{VC}<80 \%$ or $\mathrm{FEV}_{1}<70 \%$ predicted and $\mathrm{FEV}$ falls $<10 \%$ after the diluent inhalation and the patient's symptoms are well-controlled, use starting concentrations between 0.03 and $0.125 \mathrm{mg} \cdot \mathrm{ml}^{-1}$, depending on the used medication:

Medication

Starting concentration

Inhaled or ingested corticosteroids

$0.03 \mathrm{mg} \cdot \mathrm{ml}^{-1}$

Other or no medication

$0.125 \mathrm{mg} \cdot \mathrm{ml}^{-1}$

3 If a patient's FEV, falls by $10 \%$ or more after the diluent inhalation, or if asthma symptoms do not appear to be well controlled, do not omit any concentrations - start all patients at $0.03 \mathrm{mg} \cdot \mathrm{ml}^{-1}$.

If, after the first concentration of histamine or methacholine, there has been no significant fall in the FEV (less than $5 \%$ from best baseline) and there is no clinical evidence of any bronchoconstriction (chest tightness, cough or wheezing), the next dose may be omitted. Again, this can only be done if the technician is highly experienced. For example: if, after $0.03 \mathrm{mg} \cdot \mathrm{ml}^{-1}$, there are no symptoms and the fall in FEV, is less than $5 \%$, the next concentration may be $0.125 \mathrm{mg} \cdot \mathrm{ml}^{-1}$; if this produces no significant change in FEV, and there are still no symptoms, then $0.5 \mathrm{mg} \cdot \mathrm{ml}^{-1}$ may be given. As soon as there is any evidence of symptoms or the FEV, is falling: do not omit any further concentrations. Even after a fall of $5 \%$ in the $\mathrm{FEV}_{1}$, the next concentration sometimes gives quite a precipitous fall. If concentrations are omitted, it is important to stress before every 2-min inhalation that the subjects should remove the face mask/ mouthpiece as soon as they experience any breathing or chest discomfort.

The test may also be shortened by reducing the nebulization time from $2 \mathrm{~min}$ to $0.5 \mathrm{~min}$ [58]. This worsens the reproducibility of the test results [88], even though a recent study did report similar reproducibility for the $\mathrm{PC}_{20}$ obtained by $0.5 \mathrm{~min}$ and $2 \mathrm{~min}$ inhalation [89]. Furthermore, the ratio of the $\mathrm{PC}_{20}$ between the two methods has been reported to be 3.1 , in stead of the expected value of 4 [89]. Therefore, at present the $2 \mathrm{~min}$ tidal breathing method is recommended.

\subsubsection{Dosimeter method [90-93]}

Aerosols of methacholine or histamine are generated by a jet bulizer. A dosimeter is an electrical valve system, which enables one to administer aerosol during inspiration only. A flow sensor in the expiratory port triggers a solenoid which exposes the nebulizer to compressed air at $138 \mathrm{kPa}(20$ p.s.i.) for about $0.6 \mathrm{~s}$, to give a calibrated output per puff of $9.0 \mu l$ [92]. The bolus of aerosol is inhaled through the mouth from the outlet of the nebulizer during an inspiratory capacity breath over $5 \mathrm{~s}$, without breath holding at total lung capacity (TLC) [92]. This is done 5 times per concentration (total output $45 \mu l$ ) without delay. The first aerosol is diluent followed by doubling concentrations of histamine or methacholine from 0.03 to $32 \mathrm{mg} \cdot \mathrm{ml}^{-1}$ (or larger if necessary).

The doses are given at $5 \mathrm{~min}$ intervals. $\mathrm{FEV}_{1}$ is usually measured 30 and $90 \mathrm{~s}$ following each inhalation 
as for the tidal breathing method. The test is stopped when FEV has fallen by $20 \%$ or more. The tests may be shortened according to the recommendations in $\S 3.1 .4$. Results should not be calculated from cumulative breath units ( 1 unit $=1$ inhalation of aerosol from a $1.0 \mathrm{mg} \cdot \mathrm{ml}^{-1}$ solution) [90], because the non-standardized nebulizer outputs in the literature (ranging between $1.0 \mu \mathrm{l}$ [94], 2.0 $\mu l$ [95], $7.1 \mu l$ [96], $8.9 \mu l$ [91] and $9.0 \mu l$ [92] per puff) make between-centre comparisons in terms of breath units very unreliable. It is recommended to express the results in cumulative nebulized mol histamine or methacholine to cause a $20 \%$ fall in $\mathrm{FEV}_{1}\left(\mathrm{PD}_{20}\right)$ ( $\$ 3.1 .7$ and 3.1.8). Alternatively, the results can be presented as $\mathrm{PC}_{20}$, which has been reported to be similar between tidal breathing and dosimeter method when the present standardization is accomplished [92]. The reproducibility of the method is described in $\S 4.3$.

\subsubsection{Yan method [94]}

This is a hand-operated method, delivering aerosols during inspiration only. Aerosols are generated by five calibrated DeVilbiss 40 glass, handheld, nebulizers (stoppers removed) (2.2-3.8 $\mu \mathrm{l}$ per squeeze). Saline and histamine or methacholine solutions of $3.15,6.25,25$ and $50 \mathrm{mg} \cdot \mathrm{ml}^{-1}$ are placed in each nebulizer. After assessment of baseline $\mathrm{FEV}_{1}$, the saline nebulizer is placed between the teeth and the patient exhales to FRC. At the beginning of an inspiratory capacity manoeuvre to TLC lasting 1-2 $\mathrm{s}$, the operator gives the nebulizer bulb one firm squeeze. The breath is held at TLC for $3 \mathrm{~s}$, whereafter the subject exhales outside the nebulizer. This is repeated twice for saline but the number of breaths for each concentration of histamine varies according to the dose being administered, which ranges from 0.03 to $7.8 \mu \mathrm{mol}$ histamine di-phosphate or from 0.05 to $12.3 \mu \mathrm{mol}$ methacholine chloride (cumulative), or greater if needed [94]. FEV, is measured $60 \mathrm{~s}$ after each dose and the test is stopped when the FEV, has fallen by $20 \%$ or more from postsaline. Results are expressed as the cumulative dose (in $\mu \mathrm{mol}$ ) causing a $20 \%$ fall in FEV $\left(\mathrm{PD}_{20}\right)$. The reproducibility of $\mathrm{PD}_{20}$ is described in $\S 4.3$.

\subsubsection{Calculation of the response}

The airway narrowing response can be calculated as \% fall in $\mathrm{FEV}_{1}$ in two ways: taking either the post-diluent or baseline value as a reference.

\section{LOWEST POST-DILUENT FEV,}

With this method one calculates the response of the airways to either histamine or methacholine alone. The lowest, technically satisfactory [33] $\mathrm{FEV}_{1}$ measured at 30 or $90 \mathrm{~s}$ after inhalation of diluent is taken as the pretest value. The \% fall in $\mathrm{FEV}_{\text {, }}$ in response to histamine/ methacholine is $100 \mathrm{x}$

lowest $\mathrm{FEV}_{1}$ post-diluent - lowest $\mathrm{FEV}_{1}$ post-challenge lowest $\mathrm{FEV}$, post-diluent
MEAN BASELINE FEV,

With this method one calculates the overall response of the airways to the diluent + methacholine or histamine. The mean of 3 baseline measurements of $\mathrm{FEV}_{1}$ (within $5 \%$ of the largest) is taken as the pretest value. The \% fall in $\mathrm{FEV}_{1}$ in response to diluent + histamine/methacholine is

100 (mean baseline $\mathrm{FEV}_{1}$ - lowest $\mathrm{FEV}_{1}$ post-challenge) mean baseline $\mathrm{FEV}_{1}$

\subsubsection{Expression of the response}

CALCUlation OF $\mathrm{PC}_{20}$ OR $\mathrm{PD}_{20}$

$\mathrm{PC}_{20}$ is used for the tidal breathing method, whereas $\mathrm{PD}_{20}$ is the preferred index for the dosimeter and Yan method. Other outcome variables are discussed in $\S 4.1$.

Figure 3 shows the calculation of the $\mathrm{PC}_{20}$ in $\mathrm{mg} \cdot \mathrm{ml}^{-1}$ for the tidal breathing method. The method is exactly the same (including the log transformation) for the dosimeter and the 'Yan' method $\left(\mathrm{PD}_{20} \mu \mathrm{mol}\right)$. Plot the $\%$ fall in $\mathrm{FEV}_{1}$ against the concentration or dose of methacholine/ histamine on a log scale. The $\mathrm{PC}_{20}$ or $\mathrm{PD}_{20}$ is obtained by linear interpolation between the last two points, according to the formula [84]:

$$
\mathrm{PC}_{20}=\operatorname{antilog}\left\{\log \mathrm{C}_{1}+\frac{\left.\left(\log \mathrm{C}_{2}-\log \mathrm{C}_{1}\right)\left(20-\mathrm{R}_{1}\right)\right\}}{\left(\mathrm{R}_{2}-\mathrm{R}_{1}\right)}\right.
$$

where:

$\mathrm{C}_{1}=$ second last concentration $\left(<20 \% \mathrm{FEV}_{1}\right.$ fall $)$,

$\mathrm{C}_{2}=$ last concentration $\left(>20 \% \mathrm{FEV}_{1}\right.$ fall),

$\mathrm{R}_{1}=\%$ fall $\mathrm{FEV}_{1}$ after $\mathrm{C}_{1}$,

$\mathrm{R}_{2}=\%$ fall $\mathrm{FEV}_{1}$ after $\mathrm{C}_{2}$.

Extrapolation of dose-response curves should be avoided, although it may be appropriate over a dose-range not exceeding one doubling dose [97].

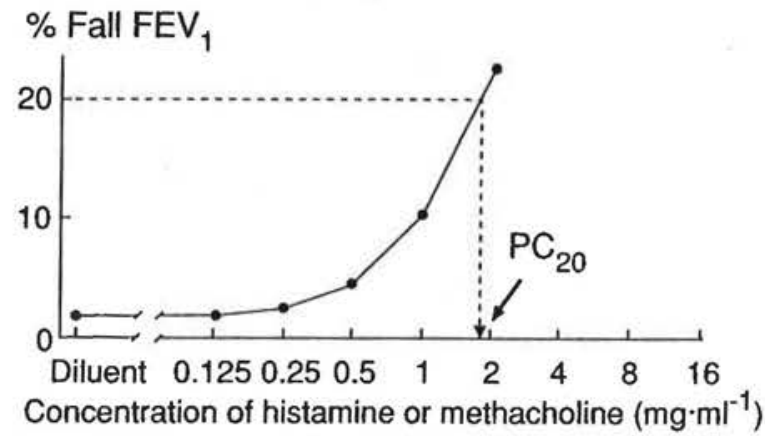

Fig. 3. - Example of the calculation of the $\mathrm{PC}_{20}$ (provocative concentration at $20 \%$ fall in FEV from baseline) from a concentration-response curve to inhaled histamine or methacholine in one subject. The $\mathrm{PC}_{20}$ is obtained by linear interpolation between the adjacent data-points. Modified with permission from reference [84].

At the recommended nebulizer output a normal $\mathrm{PC}_{2}$ for histamine and methacholine in adults is $\geq 8 \mathrm{mg} \cdot \mathrm{ml}^{-1}$ (with a "grey zone» between $4-16 \mathrm{mg} \cdot \mathrm{ml}^{-1}$ ) [60] and a normal $\mathrm{PD}_{20}$ is $\geq 7.8 \mu \mathrm{mol}[94,98]$. These are arbitrary cut-off points ( $\S 2.1$ ). It means that at these levels of airway responsiveness variable airways obstruction is unlikely at this point. The agreement between the tidal 
breathing, dosimeter, and Yan method is good [92, 94, 99], although numerical results do not always correspond due to differences in the reported units. In asthma the $\mathrm{PC}_{20}$ is similar for histamine and methacholine [83, 87], whereas the $\mathrm{PD}_{20}$ has been reported to be slightly lower for histamine as compared to methacholine in asthmatic children $[75,98](\S 3.1 .3)$ as well as in adults with COPD [100].

If two challenge tests are carried out within hours of each other, the bronchoconstrictive response to the second test may be less than to the first test, particularly when high doses are being applied [101, 102]. To minimize this tachyphylactic effect, histamine tests should be done at least $6 \mathrm{~h}$ apart. Methacholine tests should preferably be separated by $>24 \mathrm{~h}$, even though the methacholine tachyphylaxis, as observed in normals [102], could not be confirmed in asthmatics [103].

\subsection{Hypo- and hypertonic aerosols}

\subsubsection{Background}

Already in $1968 \mathrm{DE}$ VRIES et al. [58] and later, in 1980, ALIEGRA and BIANCO [104] reported that the inhalation of an aerosol of distilled water could induce an increase in specific airways resistance $\left(s R_{\mathrm{aw}}\right)$ in patients with asthma. Thereafter, ScHOEFFEL et al. [105] reported that hypertonic as well as hypotonic aerosols of saline could cause a reduction in $\mathrm{FEV}_{1}$. Over the next 10 years a number of investigators used these aerosols for the assessment of bronchial hyperresponsiveness, and the challenge procedure is now widely used [106-109].

It is now generally accepted that non-isotonic aerosols induce airway narrowing indirectly by causing the release of endogenous mediators which cause bronchial smooth muscle contraction and airway oedema. The release of mediators is thought to be directly caused by the change in osmolarity [110]. Histamine is likely to be an important mediator released because specific antihistamines are very effective in inhibiting the airway response to both hyperand hypotonic aerosols $[109,111,112]$. However, it is likely that other mediators such as the leukotrienes and prostaglandins are also involved. Further, there may be a neural component involving release of sensory neuropeptides or a parasympathetic reflex [113].

Sodium cromoglycate [114], nedocromil sodium [115] and furosemide [116, 117], drugs which are thought to affect mast cell release of mediators and/or the noncholinergic neural activity, are very effective at inhibiting airway responses to non-isotonic aerosols. The anticholinergic agents have been shown to be inconsistent in their effect and changes in baseline $\mathrm{FEV}_{1}$ due to their action as bronchodilators make the findings difficult to interpret $[114,118,119]$. The sensitivity to hypertonic saline is reduced with daily administration of corticosteroids given as aerosols [120]. This usually occurs after $400-2000 \mu \mathrm{g}$ has been taken daily for 2-8 weeks.

The responsiveness to $4.5 \%$ saline has been shown in asthmatics to correlate with numbers of mast cells obtained by bronchial biopsy [121]. The airways response to distilled water in patients with transplanted lungs has also been shown to correlate with airway inflammation [122].

There now seems to be sufficient evidence to suggest that the severity of the airway response to these aerosols reflects the involvement of inflammatory cells and their mediators in the airways [106]. Thus, in addition to demonstrating the capacity of the airways to narrow in response to the endogenous release of inflammatory mediators, challenges with these aerosols, when followed over time, may be useful in evaluating both the acute and the chronic effect of medications used in the treatment of airway inflammation.

Tests with non-isotonic aerosols are generally considered to be safe. However, there is one report of acute, fatal bronchoconstriction in response to a standardized distilled water challenge (Fabbri, personal communication). Therefore, extensive precautions must be taken ( $\$ 2.4$ ).

\subsubsection{Solutions}

The most commonly used solutions are distilled water and $4.5 \%$ saline. Some laboratories use $3.6 \%$ saline, and a concentration of $2.7 \%$ saline is usually sufficient to induce a reduction in $\mathrm{FEV}_{1}$ in very sensitive patients. Doseresponse curves are obtained by increasing the time of exposure to the single saline concentration. Alternatively, a dose-response curve can be obtained by doubling the concentration $(0.9,1.8,3.6,7.2,14.4 \%)$ [112]. This is less practical for routine purposes and should be regarded as a research procedure.

A concentration of $4.5 \%$ saline is recommended in preference to the other solutions for several reasons. The test is shorter when this concentration of saline is used compared with lower concentrations, and $80 \%$ of clinically recognised asthmatics have a $20 \%$ fall in $\mathrm{FEV}_{\text {, }}$ after $15 \mathrm{ml}$ has been nebulized or less. A person who responds to $4.5 \%$ saline usually also has exercise-induced asthma. The osmolarity is slightly above sea water, and the test is also used for screening SCUBA divers.

\subsubsection{Aerosol generation}

Ultrasonic nebulizers are recommended for generation of non-isotonic aerosols because they produce aerosols which are more dense than conventional jet nebulizers. The mass-median aerodynamic droplet size is usually between 2 and $10 \mu \mathrm{m}$ and this is reduced to less than $5 \mu \mathrm{m}$ when the breathing circuit is attached. It is recommended that a large two-way valve (Hans Rudolph 2700) be used and that the tubing attaching this to the nebulizer should have a smooth internal bore and be of constant length and diameter.

It is important to choose a nebulizer that has a reproducible output of at least $1.2 \mathrm{ml} \cdot \mathrm{min}^{-1}$ with the breathing circuit attached. Further, it is necessary to have a nebulizer with a bowl or canister which can be easily detached for weighing. A volume capacity of $100-200 \mathrm{ml}$ for the bowl is recommended. The temperature of the solution increases with time, but this is minimised with these relatively large volumes, and the small increases in 
temperature appear to have little or no effect on the response. Preferably use the same volume fill for each subject and the same setting for the nebulizer output. The output of the nebulizer and the total dose of aerosol delivered to each subject can be measured by weighing the bowl and tubing, but not the valve, before and after challenge. The valve is not weighed because of the production of saliva during the test.

For any one individual, the output of the nebulizer during the challenge is linearly related to time. Thus, to obtain the dose delivered for each exposure, it is only necessary to know the output. The output is expressed in $\mathrm{ml}$ per min. This can be obtained simply by dividing the total dose delivered during the challenge, measured by a change in weight, over the total time of exposure to the aerosol. The dose of aerosol, in $\mathrm{ml}$, delivered for each interval can be calculated from the time of exposure. For clinical purposes $1 \mathrm{~g}$ of $4.5 \% \mathrm{NaCl}$ is consideredras $1 \mathrm{ml}$ and a correction (multiply by 1.03) is not made for specific gravity.

\subsubsection{Protocol}

At present it is recommended that the dose of aerosol be increased by increasing the length of each challenge interval. Although the nebulizer output or saline concentration could be increased to achieve a higher dose, this may cause cough and be distressing to the patient (see $\S 3.2 .2$ ). In order to prevent-any problems with electrical charge in some ultrasonic nebulizers, $0.03 \%$ saline can be used instead of distilled water in case of hypotonic challenge. For hypertonic challenge $4.5 \%$ saline is recommended.

Measurements of $\mathrm{FEV}_{1}$ or specific airways resistance $\left(\mathrm{s} R_{\text {au }}\right)[2,48]$ are made in duplicate or triplicate before and between 60 and $90 \mathrm{~s}$ after each exposure to the aerosol. The exposure times are doubled as follows: $30 \mathrm{~s}$, $1 \mathrm{~min}, 2,4$ and $8 \mathrm{~min}$. If the fall in FEV, is greater than $10 \%$ of baseline the previous exposure time is repeated rather than increased. The challenge is stopped after $15 \mathrm{ml}$ is nebulized or when there is a $20 \%$ reduction in $\mathrm{FEV}_{1}$ or a doubling ( $100 \%$ increase) in $\mathrm{s} R_{\mathrm{aw}}$

Although a $20 \%$ fall in $\mathrm{FEV}_{1}$ is generally accepted as abnormal, on the basis of the findings in healthy non-asthmatic subjects, a value of $15 \%$ or more should probably be regarded as abnormal [123-126]. A bronchodilator is always administered by aerosol at the end of each challenge.

\subsubsection{Expression of the response}

The dose-response curve is constructed by plotting the change in $\mathrm{FEV}_{1}$, expressed as a percentage of the baseline value or the predicted value, against the cumulative dose of aerosol delivered, expressed in $\mathrm{ml}$ (fig. 4). The dose is calibrated according to $\S 3.2 .3$. About $15 \%$ of the measured weight loss will be deposited in the intrapulmonary airways. A value for $\mathrm{PD}_{15}$, and $\mathrm{PD}_{20}$ can be obtained by linear interpolation. Within the asthmatic population the values for $\mathrm{PD}_{20}$ are $\log$ normally distributed so the $\mathrm{PD}_{20}$ values are log transformed before a statistical analysis is carried out.
To assess changes in sensitivity after an intervention the values for $\mathrm{PD}_{20}$ are compared using log transformation. For an individual the fold difference in $\mathrm{PD}_{20}$ after an intervention can also be calculated after log transformation [120]. Because baseline lung function can be altered by treatment, or change spontaneously over time, a reactivity index (slope of the dose-response curve) can be useful. This is defined as the change in $\mathrm{FEV}_{1}$, expressed as a percentage of the predicted value, per unit dose of aerosol [120]. To compare the responses after an intervention the index is compared over the same values of percent predicted $\mathrm{FEV}_{1}$. This index can also be expressed as a fold difference. For subjects who do not reach a 15 or $20 \%$ fall in $\mathrm{FEV}_{1}$, the maximum \% fall in $\mathrm{FEV}_{1}$ and the maximum dose of aerosol delivered should be reported. A person is considered to have a severe response if the $\mathrm{PD}_{20}$ is $<2 \mathrm{ml}$, a moderate response if it is $2.1-6.0 \mathrm{ml}$, and a mild response if the $\mathrm{PD}_{20}$ is $6-20$ $\mathrm{ml}[123]$.
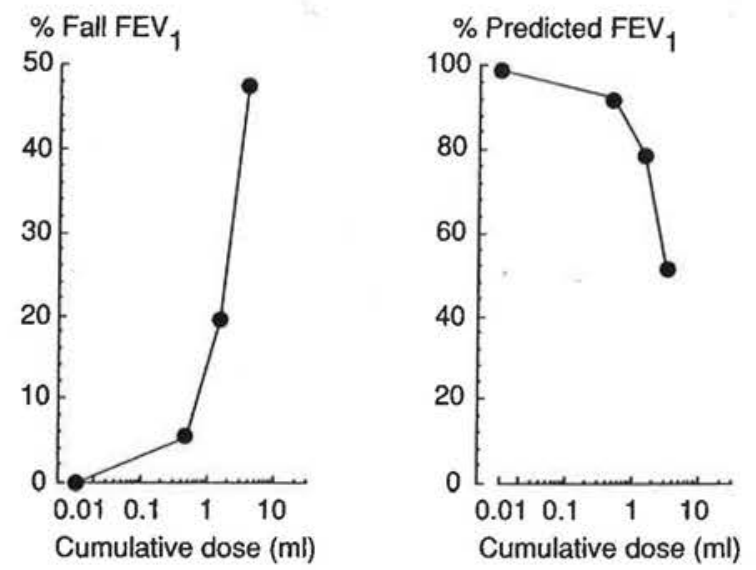

Fig. 4. - Cumulative dose of water or $4.5 \%$ saline used to provoke a fall in FEV , expressed as a $\%$ of the pre-challenge level or as a $\%$ of predicted $\mathrm{FEV}_{1}$. The cumulative dose is measured by weighing the nebulizer and tubing, but not the valve, before and after challenge. The cumulative time is recorded. The output of the nebulizer is calculated in $\mathrm{ml}$ per min. The dose for each exposure can be calculated from the time.

\subsection{Cold/dry air inhalation}

\subsubsection{Background}

Airway responsiveness can be measured by the inhalation of stimuli which cause bronchoconstriction through the release of mediators from cells within the airways, as well as by the inhalation of these bronchoconstrictor mediators. One such method is by isocapnic hyperventilation of cold and/or dry air. Although the original description of hyperventilation induced bronchoconstriction was made in 1946 [127], renewed interest in this method for inducing bronchoconstriction occurred because of the recognition that cooling and/or drying of the airways is the mechanism of exercise-induced bronchoconstriction. Airway narrowing can result from cooling and subsequently rewarming of the airway mucosa, as well as from local hyperosmolarity due to drying (reviewed in $\S 3.4$ ). The degree of airway hyperresponsiveness to isocapnic 
hyperventilation of cold dry air is moderately correlated with the degree of airway hyperresponsiveness to inhaled methacholine [128] and histamine [129] in asthmatic subjects.

Isocapnic hyperventilation of cold/dry air uses a naturally occurring stimulus to provoke bronchoconstriction rather than a chemical stimulus. Whether this implies a better safety profile still needs to be confirmed. Isocapnic hyperventilation can be administered in a dose-response fashion, and, for this reason may in some instances have advantages over exercise for measuring airway responsiveness. When giving doubling doses, the shape of the dose-response curve obtained in asthmatics is similar to other bronchoconstrictor stimuli: a lower threshold, increased slope and absence of a plateau response, when compared to non-asthmatics [130].

\subsubsection{Production and conditioning of air}

The most convenient source of air is to use dry compressed air, which is cooled by being passed over a cooling coil, through which methanol cooled to $-35^{\circ} \mathrm{C}$ is passed. This results in inspired air cooled to -12 to $-15^{\circ} \mathrm{C}$. In many laboratories, however, just dry air at room temperature is used, because this is adequate to provoke bronchoconstriction in most asthmatics, and avoids the complexities of having to cool the air. This technique leads to similar results as those with cold dry air, even though in animals studies differences between these methods have been observed [131]. Subjects inhale the cold and/or dry air through a valve. A Hans Rudolph valve can be used for this purpose, which can be divided into an inspiratory and expiratory port, if inspired and expired air temperature is being measured. If this method is used, end-tidal $\mathrm{CO}_{2}$ needs to be continuously measured in the expired air, using a capnograph, and $\mathrm{CO}_{2}$ added to the inspired air to keep the subject eucapnic.

\subsubsection{Protocol}

After measurement of baseline spirometry, the subject breathes at increasing minute volumes, beginning at 7.5 $l \cdot \mathrm{min}^{-1}$, increasing to $15,30,60 \mathrm{l} \cdot \mathrm{min}^{-1}$ and maximum minute ventilation, each period of ventilation lasting 3 min. The inspired volumes can be achieved by targeting, using a device which gives a visual display of the inspired volume. The rate of breathing is dictated either by the technician or by a metronome. The tidal volumes and rates which can be used to achieve the desired minute ventilation are: $0.75 l$ at 10 breaths/min; $1.5 l$ at 10 breaths/min; $2.0 l$ at 15 breaths/min. After each step the patient breathes room air, and the $\mathrm{FEV}_{1}$ is measured at $30 \mathrm{~s}, 90 \mathrm{~s}$, then at $3 \mathrm{~min}$ and $5 \mathrm{~min}$ and every $2 \mathrm{~min}$ until the lowest technically satisfactory value [33] is reached. The challenge is stopped once a $20 \%$ fall in FEV 1 occurs. A major limitation with the method, however, is that the maximal challenge that can be given is limited to the maximal voluntary ventilation that can be achieved by the subject being studied. On the other hand, achieving maximal ventilation may be an advantage of this technique over exercise. Although this method produces a cumulative bronchoconstrictor effect, the maximal bronchoconstriction obtained is not significantly greater than if maximal minute ventilation alone is used as the stimulus [132].

A simplified method, in which $\mathrm{CO}_{2}$ is added in a fixed amount to the inspired air $\left(\mathrm{F}_{\mathrm{I}, \mathrm{CO} 2}=0.049\right)$, prevents hypocapnia over a wide range of minute ventilations from 40 to $105 l \cdot \mathrm{min}^{-1}$ [133]. This eliminates the need to measure end-tidal $\mathrm{CO}_{2}$. However, this $\mathrm{F}_{\mathrm{I}, \mathrm{CO} 2}$ may cause hypercapnia at lower minute ventilations used in the challenge procedures $\left(7.5,15,30, l \cdot \mathrm{min}^{-1}\right)$. Therefore, with this technique the ventilation loads of $30 \%, 60 \%$ and $100 \%$ predicted maximal voluntary ventilation are used to overcome the possibility of hypercapnia. If patients with severely increased airway hyperresponsiveness are being tested, who may develop significant bronchoconstriction at these lower minute ventilations, it is necessary to monitor end-tidal $\mathrm{CO}_{2}$.

An even more simplified technique has been used in paediatrics: a single-step $4 \mathrm{~min}$ isocapnic voluntary hyperventilation at $75 \%$ of the maximal voluntary ventilation (MVV, as determined from pre-challenge $\mathrm{FEV}_{1}$ ) of cold dry air $\left(-10^{\circ} \mathrm{C}\right)[134]$. Since in adults there are no comparative studies of this test with the multiple-step protocol, at this stage, the dose-response approach is recommended.

\subsubsection{Expression of the response}

The response is measured as the change in FEV from the baseline values. A dose-response curve is obtained by plotting the incremental increase in minute ventilation $\left(V_{\mathrm{E}}\right)$ against the change in $\mathrm{FEV}_{1}$, (usually $10 \%$ or $20 \%$ fall), and the response expressed as the $\mathrm{P} V_{\mathrm{E}, 10}$ or $\mathrm{PV}$ (the provocative minute ventilation causing a $10 \%$ or $20 \%$ fall in $\mathrm{FEV}_{1}$, respectively). If cold dry air is being used as the stimulus, some investigators have calculated the respiratory heat exchange (RHE) [135]. This requires the measurement of the inspired and expired air temperature, using rapidly responding thermocouples, and water content. If dry air is used, then the water content is 0 $\mathrm{mg} \cdot l^{-1}$. The expired air is assumed to be fully saturated, and therefore the water content can be obtained from standard graphs of air temperature and humidity. A doseresponse curve is obtained by plotting the incremental increase in RHE ( $\left.\mathrm{kcal} \cdot \mathrm{min}^{-1}\right)$ against the change in $\mathrm{FEV}_{1}$, and the results expressed as the RHE giving the predetermined fall in $\mathrm{FEV}_{1}$. However, in most instances, when just dry air is used as the stimulus, reporting minute ventilation is sufficient and the respiratory heat exchange does not need to be calculated.

A fall in $\mathrm{FEV}_{1}$ of at least $10 \%$ is generally required to indicate a positive result to the challenge. The magnitude of this response is greater than 2 standard deviations above the response seen in normal subjects $[135,136]$.

\subsection{Exercise}

\subsubsection{Background}

It is now 30 years since JONES [137] described the effects of exercise on the airways resistance in children with 
asthma. This exercise-induced bronchoconstriction is usually referred to as exercise-induced asthma (EIA), even though it is generally accepted that exercise is not an inducer, but an inciter of asthma. By the early 1970's, GODFREY and his colleagues had identified many of the factors which determined the severity of the airway response [138]. These included the type of exercise, its intensity and duration, and the interval since exercise had last provoked an attack of asthma. By the late 70's it was recognised that the most important determinant was the level of ventilation which was reached and sustained during exercise. It was noted that exercise in itself was not necessary to provoke an attack of asthma, and hyperventilation alone could achieve the same response [139]. At the same time the effects of temperature and water content of the inspired air were being investigated. It was discovered that exercise-induced asthma could be completely inhibited when air at body temperature and water vapour was inhaled during exercise [140]. Thus it was concluded that the stimulus for EIA had to be the loss of either heat or water or both from the airways during exercise.

Initially it was considered that cooling of the airways was the stimulus [141] but later studies demonstrated that water loss was more important than heat loss. From these studies it was proposed that transient hyperosmolarity of the airway surface liquid as a result of evaporative water loss was the stimulus to EIA [142]. It was also demonstrated in vitro that an increase in osmolarity provided an ideal environment for the release of mast cell mediators [143]. These mediators have the potential to cause the airways to narrow by contraction of bronchial smooth muscle. A more recent proposal has suggested that vascular engorgement and oedema of the bronchial circulation is more important than bronchial smooth muscle contraction in causing the airways to narrow [144, 145]. At present there is no direct evidence to support either of these two hypotheses, and further studies are required to clarify this important issue [146].

Exercise provokes an attack of asthma in 70 to $80 \%$ of the population with clinically recognized asthma. In clinical situations exercise tests are not very sensitive, but are highly specific for the diagnosis of asthma, and are particularly useful in children [147-149]. It may not be very practical in older patients. In field studies, exercise tests are less specific for the diagnosis of asthma [150], showing a prevalence of positive responses between 7 and $16 \%[150,151]$. EIA may occur at any age and is equally common in adults and children. The signs and symptoms of EIA do not differ from other forms of acute asthma except that they are of short duration. In addition to increasing airways resistance exercise can induce a transient hyperinflation and arterial hypoxaemia. The majority of persons recover spontaneously from an attack of EIA within $30 \mathrm{~min}$ while a minority require oxygen and bronchodilators given by nebulization. In $50 \%$ of persons EIA is followed by a refractory period of about 1 hour [152]. The occurrence of a late asthmatic response, several hours after exercise is rare and their association with exercise itself is still a controversial issue $[153,154]$.
EIA is prevented in most asthmatic patients by premedication with sodium cromoglycate, nedocromil sodium or a $\beta$-adrenoceptor agonist [152, 155-158]. In some cases a combination of both types of medication is required. In difficult cases the dose of these agents is doubled and ipratropium bromide added.

\subsubsection{Experimental set-up}

In the laboratory exercise should be carried out on either a bicycle ergometer or a motor-driven treadmill. There are definite advantages in using a bicycle in that the head is stable and it is easier to administer dry gas and collect expired air. Further, the work intensity during cycling, but not running, is independent of body weight, making it easier to predict the workload required to achieve the target ventilation.

The ventilation in litres per minute should be measured at least during the last $4 \mathrm{~min}$ of exercise. The time of exercise should be 6 to $8 \mathrm{~min}$.

Heart rate should be monitored continuously and in the case of persons over $40 \mathrm{yr}$ of age an electrocardiogram should be taken throughout exercise and for $5 \mathrm{~min}$ after its completion.

Changes in airways resistance are best measured indirectly by documenting changes in FEV, or PEF. Although PEF is easier to measure, $\mathrm{FEV}_{1}$ is recommended as it reflects a larger proportion of the flow-volume curve.

It is strongly recommended that air inspired during exercise has a water content as low as possible and less than $10 \mathrm{mg}$ per litre (relative humidity less than $50 \%$ between $20-25^{\circ} \mathrm{C}$ ). The best way to achieve this is to have the subject inspire compressed medical air at room temperature via a demand valve and regulator. Although some laboratories generate air of subfreezing temperatures there is no need to have expensive equipment to condition the inspired air. Providing the inspired air is dry it is only necessary to increase the time of the exercise to increase the severity of the airway response.

Medication and baseline lung function alter the response to exercise and need to be taken into consideration when planning the protocol. Measurements of FEV, should be made on arrival in the laboratory and the stability and reproducibility of the value established. The best values should preferably not vary by more than $10 \%$; the absolute value should be within $80 \%$ of the subject's usual value and preferably better than $75 \%$ of their predicted value. The subject should have withheld the medications according to recommendations in $\S$ 2.3 .

\subsubsection{Protocol}

The highest of the $\mathrm{FEV}_{1}$ measurements taken immediately before exercise is recorded and used in the calculations. The work intensity is selected for the subject to achieve between $40 \%$ to $60 \%$ of their predicted maximum voluntary ventilation (which can be taken as FEV, predicted.35) during the last $4 \mathrm{~min}$ of exercise. The oxygen 
consumption to achieve this ventilation can be estimated from the equation relating these measurements in children and in adults [156]. The work load to achieve this oxygen consumption is then determined from the equation. For the furst minute the work load is set to $60 \%$ of the target load. This is increased to $75 \%$ in the second $\mathrm{min}, 90 \%$ in the third min and $100 \%$ in the 4 th minute. When the subject has achieved the target level of ventilation or reached the ventilatory or working capacity the work load is sustained for $4 \mathrm{~min}$. Minor adjustments may need to be made to this work load but this protocol is good both for general laboratory use and for research [157, 158]. A pilot exercise study may be needed, since it seems unnecessary to have responses above $30 \%$ fall in FEV, if repeated tests are required.

To select a work load for running on a treadmill it is necessary to know the weight of the subject. It is usual to aim for a speed and slope on the treadmill which will induce $30-45 \mathrm{ml}$ of oxygen consumption per kilogram. Running at $5-9 \mathrm{~km} / \mathrm{h}(3-5 \mathrm{mph})$ up a $10 \%$ incline is usually sufficient work for most subjects. Once the target ventilation is achieved it should be sustained for $4 \mathrm{~min}$ if possible.

The subject must have the nose clipped to ensure mouth breathing. The measurements of $\mathrm{FEV}_{1}$ are made in duplicate after exercise at $1,3,5,7,10$ and $15 \mathrm{~min}$ and the highest value at each time is recorded [156]. A bronchodilator is always given by aerosol upon completion of the protocol.

\subsubsection{Expression of the response}

The $\%$ fall index is the most widely used term to express the severity of EIA (fig. 5). It is calculated by subtracting the lowest value of the measurement of FEV, recorded after exercise and expressing it as a percentage of the value recorded immediately before exercise. A fall in $\mathrm{FEV}_{1}$ of $10 \%$ or more of the pre-exercise value should be considered abnormal when tests are being performed in the laboratory. However, in the field a fall of $15 \%$ or more is used [155]. If measurements are made during exercise (this is now unusual) the \% rise index can be calculated. This is calculated by subtracting the value recorded immediately before exercise from the highest value measured during exercise and expressing it as a percentage of the value measured before exercise. The exercise lability index is the sum of the \% fall and the \% rise and is an excellent index for characterising airway responsiveness to exercise (fig. 5) [138].

It is recommended that in addition to the \% fall index, the pre-exercise value for $\mathrm{FEV}_{1}$ and the lowest value after exercise be reported in \% predicted. In this way the clinical relevance of response to therapy is more easily ascertained [159].

The ventilation required to induce the observed \% fall in FEV, is also reported and is useful for assessing the effect of therapy. Reporting values for heat and water loss has little meaning in clinical practice. The recording of a potential late response is not recommended, because the interpretation of a fall in lung function at about 3-8 h after exercise is still unclear [153, 154].

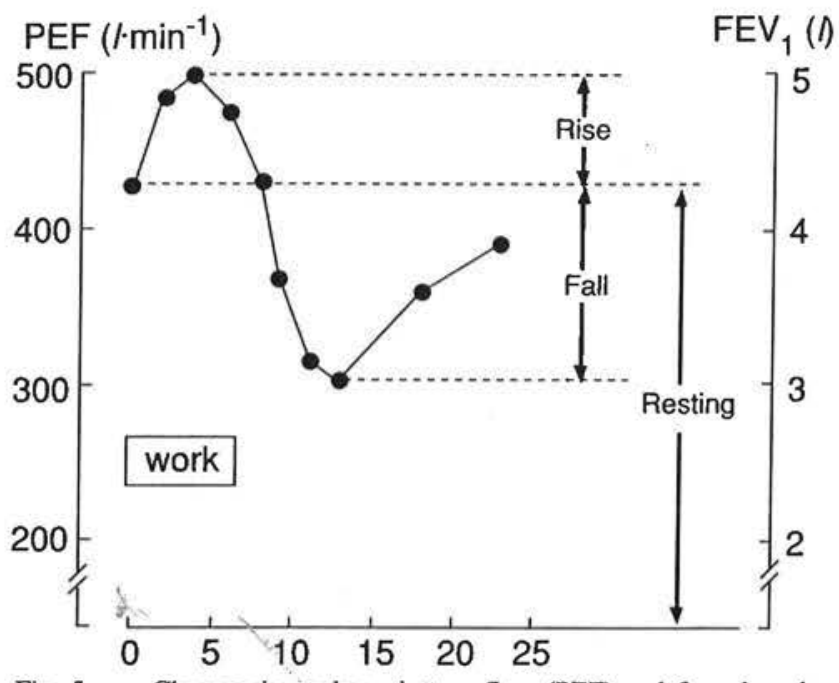

Fig. 5. - Changes in peak expiratory flow (PEF) and forced expiratory volume in one second (FEV, recorded during and after exercise in an asthmatic person who has some airflow limitation at rest. The highest, lowest, and pre-exercise values are used to calculate the $\%$ rise and \% fall. Modified from Anderson [152], with permission.

\subsection{Allergen inhalation test}

\subsubsection{Background}

The airway response to allergen and chemical sensitizers (§ 3.6) is more complex than that to the bronchoconstrictive triggers covered above in $\S 3.1$ to 3.4 . The early asthmatic response (EAR) is an episode of airflow obstruction, predominantly airway smooth muscle contraction, maximal between 10 and $20 \mathrm{~min}$ after inhalation and resolving within 90 to $120 \mathrm{~min}$ [160]. The late asthmatic response (LAR) is an episode of airflow obstruction, probably caused by both airway smooth muscle contraction and inflammation, occurring between 3 and $\geq 8 \mathrm{~h}$ after inhalation [38, 160]. Allergen-induced increase in airway responsiveness to histamine or methacholine $\left.\Delta \mathrm{PC}_{20}\right)$, likely an indirect measure of allergen-induced inflammation, occurs between $3 \mathrm{~h} \mathrm{[161]}$ and several days [162] after allergen exposure, chiefly in subjects manifesting late asthmatic responses. Controlled standardized allergen inhalation tests have a limited, if any, role clinically. They may be helpful in confirming allergic asthmatic responses in exceptional cases where immunotherapy is contemplated. However, they are of great value in research, both for investigating the pathophysiology of asthma [161-163], and studying new, particularly prophylactic, pharmacological agents $[164,165]$. The allergen inhalation test protocol outlined below takes into account the three aspects noted above: EAR, LAR, and change in $\mathrm{PC}_{20}[160,162-165]$. Standardization is directed primarily towards within-subject reproducibility, which is particularly relevant to research studies. Under all circumstances extensive precautions are needed for safety requirements ( $\$ 2.4)$.

\subsubsection{Solutions and dose range}

Solutions for allergen inhalation are made from the best available commercial aqueous allergen standardized 
extracts. These must be carefully standardized according to recent recommendations [166]. The stock solutions should preferably have a concentration of 10,000 biological units $(\mathrm{BU})$ or 10 histamine equivalent prick test (HEP) per $\mathrm{ml}\left(1000 \mathrm{BU} \cdot \mathrm{ml}^{-1}=1 \mathrm{HEP}\right)$. In weight/volume $(\mathrm{w} / \mathrm{v})$ this ranges approximately from 1:10-1:20 w/v (pollen and animal danders) to 1:50-1:100 w/v (housedust mite). Stock solutions are diluted 1:8 with sterile buffered carbol isotonic saline containing $0.5 \%$ phenol. Thereafter, serial doubling dilutions $(1: 16,1: 32, \ldots \geq$ $1: 1024)$ are made. The weakest allergen solution used for allergen inhalation is determined by the skin test endpoint ( $\S 3.5 .4$ ) in the individual undergoing challenge [167], and may be as dilute as $1: 65,536$. The most concentrated solution used for inhalations is usually the $1: 8$ dilution; this represents $1250 \mathrm{BU} \cdot \mathrm{ml}^{-1}$ or $1.25 \mathrm{HEP}(1: 80$ $\mathrm{w} / \mathrm{v}$ dilution for pollen extracts to $1: 800 \mathrm{w} / \mathrm{v}$ dilution foi house-dust mite extract). Stability of particularly the weaker allergen concentrations is important, and is assured by freshly mixing allergen dilutions before each inhalation challenge.

\subsubsection{Aerosol generation}

Aerosols are generated with a jet nebulizer (driving pressure up to $344 \mathrm{kPa}$ or 50 p.s.i.) calibrated with airflow between 4 and $9 \mathrm{l} \cdot \mathrm{min}^{-1}$, to give a mass loss of $0.13 \mathrm{~g} /$ min (approximately equivalent to $0.13 \mathrm{ml} \cdot \mathrm{min}^{-1}$ ). A closed system should be used to prevent inadvertent allergen exposure and sensitization of laboratory personnel. The nebulizer is connected to a Hans-Rudolph box and valve system, and to the patient by a mouthpiece. Two ventilator breathing circuit filters are placed in series on the expiratory line to trap the uninspired nebulizate, and the exhalate.

\subsubsection{Protocol}

A control day is important to ensure stability of FEV, (within $10 \%$ of baseline) over the 8 to $10 \mathrm{~h}$ of the study. On the control day, diluent is inhaled for $2 \mathrm{~min}$ at $10 \mathrm{~min}$ intervals on three occasions. $\mathrm{FEV}_{\text {, }}$ is measured initially in triplicate and in duplicate $10 \mathrm{~min}$ after each inhalation, and following the last inhalation, every $10 \mathrm{~min}$ for the first hour, at $90 \mathrm{~min}$ and 2 hours, and then hourly up to $7 \mathrm{~h}$ after challenge. On the control day, duplicate prick skin tests with the doubling dilutions of allergen for inhalation are done in order to determine the skin test endpoint, i.e. the weakest concentration producing a wheal of $2 \mathrm{~mm}$ or $2 \mathrm{~mm}$ larger than control. A histamine or methacholine $\mathrm{PC}_{20}$ is measured at $7 \mathrm{~h}$. The severity of the early asthmatic response $\left(\mathrm{PC}_{20, a l l e r g e n}\right)$ can be predicted from the skin test endpoint and the histamine or methacholine $\mathrm{PC}_{20}$ [167]. This is highly relevant for safety purposes. It is being done with the following formula:

$$
{ }^{10} \log \left(\mathrm{PC}_{20, \text { allergen }}\right)=0.68 \cdot{ }^{10} \log \left(\mathrm{PC}_{20, \text { histamine }} \cdot \mathrm{SS}\right)
$$

where SS = the skin test endpoint.

On the allergen challenge day, allergen inhalations are commenced starting two to four concentrations below the predicted $\mathrm{PC}_{20, \text { allergen }}$. Doubling concentrations of allergen are inhaled for $2 \mathrm{~min}$ at $10 \mathrm{~min}$ intervals until the $\mathrm{FEV}_{1}$ measured at $10 \mathrm{~min}$ has fallen by $\geq 15 \%$, or until the top concentration has been reached. If the $\mathrm{FEV}_{\text {, falls by }}$ $<10 \%$, the next concentration is inhaled. If the FEV, falls between $10-15 \%$, the next concentration should be inhaled for $1.5 \mathrm{~min}$ rather than $2 \mathrm{~min}$. Only if the fall in $\mathrm{FEV}_{1}$ is still $<15 \%$ should the concentration be inhaled for $2 \mathrm{~min}$. This is an effort to minimize the maximal fall in $\mathrm{FEV}_{1}$ after inhaled allergen. Since the EAR progresses for $\geq 20 \mathrm{~min}$, even the slightest of symptoms occurring during allergen inhalation is an indication for immediate discontinuation of inhalation. The FEV, is monitored for at least $7 \mathrm{~h}$ as on the control day. It should be emphasized that this monitoring is always required, because even in the absence of an EAR a LAR can not be excluded. The patient then receives written instructions about the medical care during the first $24 \mathrm{~h}$ after the challenge ( $\S$ 2.4). In exceptional cases, only the EAR is of interest. Then the patient should be given a $\beta$-agonist either or not combined with inhaled steroids following the EAR. After full recovery from the EAR the patient is allowed home with adequate instructions on measurements of PEF and medical care during the first $24 \mathrm{~h}$.

Allergen-induced increase in airway responsiveness can be addressed by measuring histamine or methacholine $\mathrm{PC}_{20}$ at $3 \mathrm{~h}$ (between the early and late response), or the next day at 24 to $32 \mathrm{~h}$ after inhalation. Repeat measurements of $\mathrm{PC}_{20}$ may be made over several days if indicated.

Repeat allergen inhalation tests, generally under experimental conditions, are done with the same dose of allergen throughout, since the cumulative allergen dosage determines the response of the subjects [168]. Both for safety and consistency in timing of pre-allergen medications, one should strive to have three inhalations up to and including the final concentration of allergen delivered for each test. Repeat tests are done $a \geq 7$ day intervals when the baseline $\mathrm{FEV}_{1}$ is stable (within $\pm 10 \%$ ), the histamine or methacholine $\mathrm{PC}_{20}$ measured before the test is stable (within \pm one doubling dilution), and there has been no natural allergen exposure or respiratory tract infection for $\geq 4 \mathrm{wk}[164,167]$. In contrast to repeat histamine/methacholine challenges under experimental conditions, e.g. in situations where the early response is being inhibited by an agent such as a $\beta_{2}$-agonist, one should not aim to achieve a fall in FEV, of $20 \%$ during the EAR because of the possibility of severe prolonged late responses. It also needs emphasis that the so-called anti-inflammatory drugs have profound effects on early and late asthmatic responses [164]. Continuous personal attendance by a physician is required during the challenge, and for the duration of the early asthmatic response. Complete cardiopulmonary resuscitation equipment must be readily available including particularly parenteral adrenaline (drawn up and ready to use) and inhaled $\beta$ agonists (see $\S 2.4$ ). These tests should only be carried out in a hospital setting.

\subsubsection{Expression of response}

The best $\mathrm{FEV}_{1}$ at each time is retained for analysis. A typical example of time-response curves is illustrated in 
figure 6. The EAR is defined as the maximum per cent reduction in $\mathrm{FEV}_{1}$ (\% fall from baseline) occurring in the first hour after challenge. The magnitude of the LAR is defined as the maximum per cent reduction in FEV, occurring between 3 and $7 \mathrm{~h}$ after challenge. An alternative way to express the EAR is the $\mathrm{PC}_{20}$ [leren [167]. In addition, some investigators express the EAR and LAR as the area under the time-response curve [169]: the advantage of this type of analysis is the inclusion of all data-points on the time-response curve. Allergen-induced increase in airway responsiveness is generally defined either as the difference in $\log \mathrm{PC}_{20}$ or as the pre/post $\mathrm{PC}_{20}$ ratio using logarithmic transformation for statistical analyses.
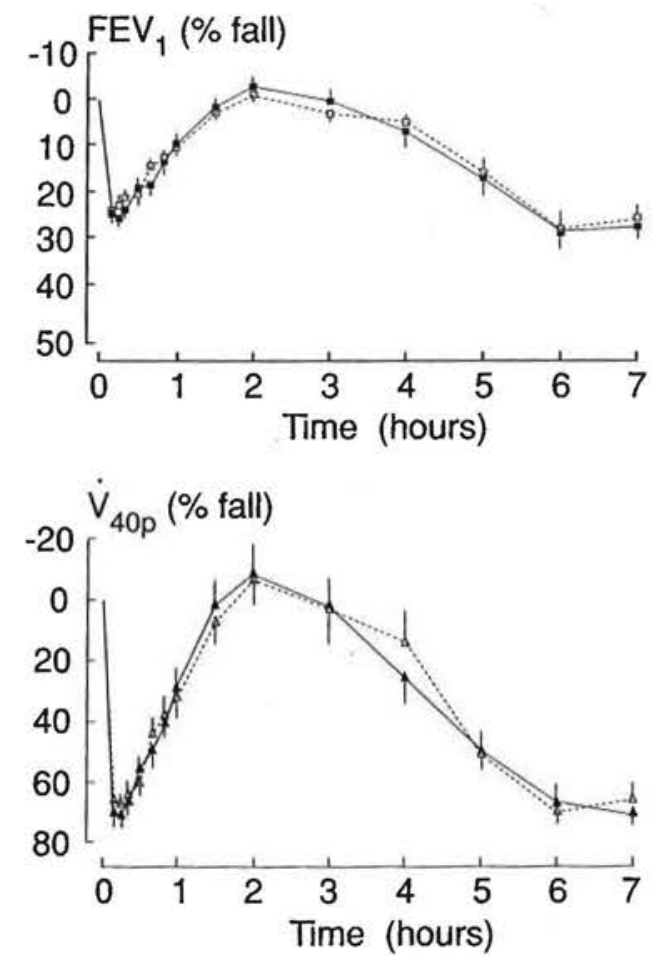

Fig. 6. - Mean ( \pm SEM between subjects) time-response curves of FEV (squares, upper panel) and of expiratory flow obtained from partial flow-volume curves $\left(V^{\prime}{ }_{40}\right)$ (triangles, lower panel) after an allergen challenge with inhaled house-dust mite extract in 10 atopic asthmatic subjects on 2 days (open and closed symbols) separated by a 2 weeks interval. When using the present standardization, the reproducibility of the early and late asthmatic response appears to be good. Modified from BeL et al. [249], with permission.

\subsection{Occupational sensitizers}

\subsubsection{Background}

DEFINTTION OF OCCUPATIONAL ASTHMA

Occupational asthma is caused by a specific «sensitizing» agent present at the workplace [170-172]. Asthma of occupational origin may also be caused by an acute exposure to strong respiratory irritant gases at work, a syndrome named «reactive airway dysfunction syndrome» [173-175]. An extensive list of these agents causing occupational asthma has been published in recent review articles [e.g. 170-172].
DiAGNOSIS OF OCCUPATIONAL ASTHMA

A correct collection of patient's history is the most important step for the diagnosis of occupational asthma [170 172]. Repeated measurements of peak expiratory flow performed at home and at work over several weeks, may provide objective confirmation of a suggestive history of occupational asthma [176, 177]. Although skin tests and specific IgE, when available, are not diagnostic for disease, they may be useful to diagnose sensitization to high molecular weight occupational sensitizers.

In subjects with occupational asthma the degree of airway responsiveness to methacholine or histamine is usually increased [170-172] and remains increased after cessation of exposure $[178,179]$, but it may also be normal, particularly when the subject is examined after a period of non-exposure $[180,181]$.

The specific bronchial provocation tests are presently considered as the «gold standard» for the confirmation of occupational asthma [170-172, 182-184], even though false positive or false negative challenges can occur $(\S$ 3.6.5). Extensive safety requirements are needed (see $\S$ 2.4 and $\S 3.6 .5)$.

\subsubsection{Agents}

SPECIFIC BRONCHIAL PROVOCATION TESTS WITH OCCUPATIONAL AGENTS

In subjects with reproducible measurements of lung function on a control day, usually 2 or more inhalation challenges are performed on different days, starting with exposure to the diluent or a control product (e.g. filtered air, PBS, chemical diluent, lactose), followed by exposure to increasing concentrations of the occupational agent. Specific bronchial provocation tests with occupational agents may cause early, late, or dual asthmatic and atypical reactions [182-184].

In some cases it is not possible or ethical to perform specific bronchial provocation testing, either because they are risky due to poor baseline lung function, or the general physical conditions of the subject, or because of poor reproducibility of lung function measurements, or simply because some subjects refuse to perform such tests. In these cases other diagnostic approaches must be undertaken to establish the diagnosis. Combined monitoring of lung function parameters, such as PEF at the worksite and of histamine or methacholine airway hyperresponsiveness may provide alternative approaches in these cases $[176,177,185]$; these approaches require further study before they are accepted as definitive and do not actually represent true alternatives to specific bronchial provocation testing [184].

While specific bronchial provocation tests have been used increasingly in clinical practice, some of these tests performed with suspected causative agents for which there has been little previous experience are still considered research procedures, and more validation of their sensitivity, specificity, and reproducibility may be needed before they can be recommended for general clinical use.

Sensitivity, specificity and reproducibility have been reasonably established for bronchial provocation tests with only few agents, such as toluene diisocyanate (TDI) or 
soluble agents. The specificity of TDI challenge has been demonstrated by the fact that non-exposed control subjects with asthma with documented airway hyperresponsiveness are nonreactive to TDI challenge at 15 to $20 \mathrm{ppb}$ [185]. The reproducibility of the TDI challenge procedure has been demonstrated to be reasonable [186]. Therefore, as an example, most details on the methodology discussed below refer to TDI-challenge.

\subsubsection{Dose delivery}

NATURE OF THE AGENT

Agents soluble in water or safe diluent, dust, or vapours can be used for inhalation challenge testing with occupational agents. One should always ensure that the correct chemical is used. All calibration and monitoring devices should be regularly checked.

WATER SOLUBLE HIGH MOLECULAR WEIGHT ALLERGENS The methodology to be used with these agents is the same as the one being used for bronchial provocation tests with common allergens.

\section{AGENTS IN POWDER OR DUST FORM}

The method of tipping powder from one tray onto another, used in the past, should not be used anymore, because it does not allow for monitoring of the concentration of particles in the air. Indeed, as for all occupational agents, the levels of dust to which the subjects are exposed should never exceed the short-term exposure limit (TLV-STEL) set by the American Conference for Governmental Industrial Hygienists (ACGH) [187]. A recently developed apparatus makes exposure to steady and low concentrations of particles possible and permits monitoring of the diameter of the particles (fig. 7) [188190]. This consists of a particle generator, an exposure chamber with elimination system, and photometer- and cascade-impactor monitoring devices, all being automated using closed-loop feedback, regulated by computer programme $[189,190]$.

\section{VAPOURS}

Challenges with vapours or gases have so far been performed by various investigators in challenge rooms that are similar to each other (fig. 8) [191-193]. The rooms are usually well ventilated with a circuit near the ceiling, so that the air in the antechamber and challenge rooms can be completely changed within a few minutes.

After the control days required for assessment of reproducibility of lung function measurements, and to exclude airflow obstruction induced by nonspecific mechanisms, subjects are usually exposed to increasing concentrations of the vapour or gas. For polyisocyanates, for example, exposure may be performed in one of the following ways depending on the type of isocyanate:

1 for TDI: $20-100 \mathrm{ml}$ of pure commercial TDI $(80 \%$ 2.4-TDI and 20\% 2.6-TDI) is deposited in a small cup within a bottle, and air is passed through and dispersed in the exposure room;

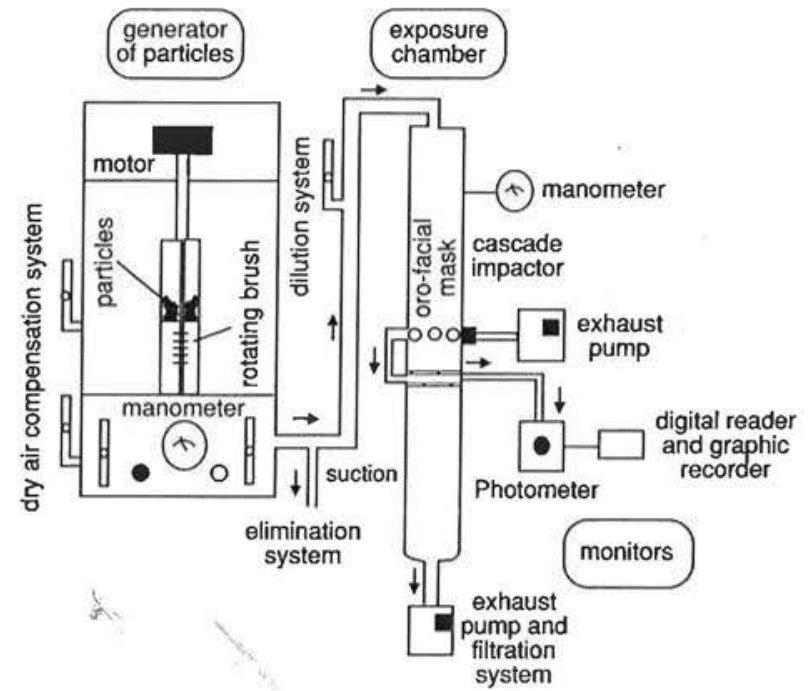

Fig. 7. - Aerosolization device made in three parts: 1) the particles generator on the left end where the powder is vibrated, taken to the rotating plate by an endless screw and sucked out; 2) the exposure of aerosol delivery chamber, a long plexiglass cylinder with three holes in the centre, one for the facemask, one for the photometer probe and one for the cascade impactor probe; 3 ) the recording instruments: the photometer and the cascade impactor. Modified from Cloutier and Malo [189], with permission.

2 for HDI (hexamethyl diisocyanate), the commercial preparation the subject is exposed to at work (from $20 \%$ to $75 \%$ of $\mathrm{HDI} / \mathrm{HDI}$ biuret, depending on the product) is nebulized with the diluent (1:3 concentration) using a plastic or glass nebulizer;

3 for MDI (methylene diphenyl diisocyanate): the commercial preparation containing $40 \%$ to $50 \%$ of MDI and $50 \%$ to $60 \%$ of polyethylene polyphenyl isocyanate is heated in a metal cup to approximately $80^{\circ} \mathrm{C}$.

The isocyanate concentration may be monitored by automatic monitor (MDA-7050 or MDA-7100). The monitor is usually put in the adjacent challenge room as contamination of the recording paper can occur if the monitor is located in the same room as the source of isocyanate. The tip of the sampling tube of the MDA7100 monitor crosses the window and is put at a distance equivalent to that which separates the source of polyisocyanates from the subject's mouth. By controlling the ventilation in the room and the output of the nebulizer, the technician can stabilize the concentration of polyisocyanates in the challenge room and keep it below the threshold limit value for short term exposure level (e.g. TLV-STEL which is $20 \mathrm{ppb}$ for isocyanates) [187]. The humidity in the chamber should be kept close to $50 \%$ (the reading of polyisocyanates by the MDA-7100 monitor is affected by humidity). A ventilator can homogenize the isocyanate in the air.

A self-contained apparatus including a closed-circuit mixing chamber has recently been developed which allows delivery of controlled concentrations of gaseous isocyanates at the mouth of the subject, without the need of a cumbersome exposure chamber [194]. This alternative approach is promising, and deserves further validation. 


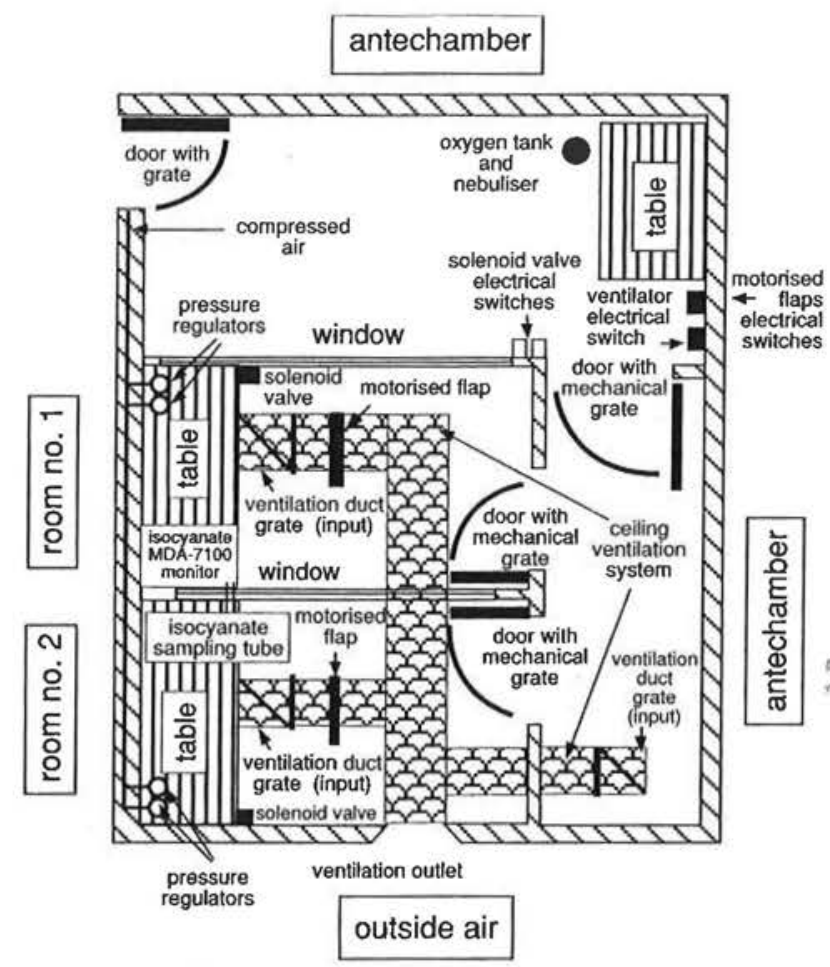

Fig. 8. - The challenge rooms used at the Hôpital du Sacré-Coeur (Montreal, Canada) for the last few years. There are two antechambers and two challenge rooms. The ventilation system in the ceiling of the rooms is shown by transparency. Two large plexiglass windows allow the technician located in the antechamber at the top of the figure to have a direct access to the ventilation and solenoid valve regulators to control aerosolization within the challenge rooms. For challenges with polyisocyanates, a MDA-7100 monitor is placed in room 1, adjacent to room 2 where the subject sits. The small sampling tube crosses the plexiglass window between rooms 1 and 2.

\subsubsection{Level and duration of exposure}

After the control day of assessment of reproducibility of lung function, the subjects are usually exposed to a control chemical (e.g. for TDI challenge it would be the chemical that is usually mixed with polyisocyanates) for a total of $15 \mathrm{~min}$ in a challenge room. This allows to verify that the reaction to the «sensitizer» is specific and not due to nonspecific irritation.

The principle is to generate a dose-response curve by increasing the duration and/or the concentration of exposure on different days. The duration of exposure to a very low concentration should be increased progressively for the first day of exposure (e.g. 1, 5, 10, $15 \mathrm{~min}$ exposure to $1 \mathrm{ppb}$ TDI). If there is no asthmatic reaction (see below), the duration and/or the concentration of exposure may be increased in different days (e.g. 1, 5, 10 , and $15 \mathrm{~min}$ to $5,10,20 \mathrm{ppb}$ TDI, respectively) during the following 3 days.

In principle, the overall concentration should not exceed the threshold limits value for short-term exposure (TLV-STEL) recommended by the ACGIH [187].

The duration and intensity of exposure to the suspected offending agent should be dictated by clinical history. If there is any indication of a severe immediate reaction, short exposure under controlled conditions should be considered. The level of bronchial obstruction and nonspecific airway responsiveness are also helpful in determining the duration and level of the initial exposure [195].

\subsubsection{Expression of the response}

$\mathrm{FEV}_{1}$ is more sensitive than the simpler PEF in detecting the response [196]. To be considered positive, investigators generally require a fall of $20 \%$ or more in FEV, at the time of an immediate reaction with progressive recovery in the first hour, or a sustained fall in FEV, of at least $20 \%$ in the case of non-immediate reactions, both in the absence of significant changes on the day of exposure to the control product.

$\mathrm{FEV}_{1}$ is usually assessed for at least $8 \mathrm{~h}$, i.e. every 10 $\mathrm{min}$ for the first hour, every $30 \mathrm{~min}$ for the second hour and then hourly. Subjects are also asked to continue measuring at least PEF during the evening or during the night in order to investigate whether airway obstruction occurs after the usual period of $8 \mathrm{~h}$ monitoring.

An increase in histamine or methacholine airway responsiveness typically occurs after late reactions, but it may also occur after immediate asthmatic reactions [185, 197-201]. Airway responsiveness may also increase without significant changes in $\mathrm{FEV}_{1}$. In these cases a longer exposure to the specific agent can induce bronchoconstrictive reaction [200].

\section{PATTERNS OF REACTION}

As with bronchial provocation tests with allergens, immediate, late and dual reactions may develop after a specific bronchial provocation test with occupational agents [182, 184].

Atypical reactions, particularly after exposure to polyisocyanates, may also develop [184], mainly of the progressive type (starting within a minute after exposure ended, progressing to a maximum 7 to $8 \mathrm{~h}$ later). In addition, there are «square wave» reactions, i.e. no recovery between the immediate and late components of the reaction. Two "progressive recovery» patterns were also seen where subjects had maximum bronchoconstriction immediately after exposure to polyisocyanates [184].

\section{SAFETY}

The same safety procedures that apply to bronchial provocation tests with allergens apply to bronchial provocation tests with occupational sensitizers ( $\$ 2.4 .1$ and 2.4.2). In particular, it is important to ensure that the asthmatic subject is in a reasonably steady state $\left(\mathrm{FEV}_{1}\right.$, fluctuations should be less than $10 \%$ throughout an observation period of $8 \mathrm{~h}$ on the control day), and that medications are kept constant for subjects who require continuous medication (see also § 2.3). It needs to be emphasized that the socalled anti-inflammatory drugs have profound effects on early and late asthmatic responses to sensitizing agents. If $\mathrm{PC}_{20} \mathrm{FEV}$, to methacholine is $<1 \mathrm{mg} \cdot \mathrm{ml}^{-1}$ there is an increased risk of severe reactions to isocyanates [195], which thereby should be considered as a relative contraindication. 
FALSE POSITTVE AND FALSE NEGATTVE REACTIONS

Even if specific inhalation challenges are the gold standard, false positive or false negative tests can occur.

With immediate reactions, it is sometimes difficult to distinguish between a nonspecific reaction and a reaction similar to one that could occur after exposure to a proper sensitizing agent. Indeed, the pattern of reaction in terms of peak effect and recovery is similar to one that has been described for non-specific reactions such as exercise and hyperventilation [153]. The use of a control «irritant» substance (lactose for powders, the vamish usually mixed with polyisocyanates, etc.) is suggested and using an apparatus that gives information on the concentration and diameter of the particles and polyisocyanates. False positive late reactions can also be observed in subjects in an unstable clinical condition. This is the reason why subjects should always be observed on a control day to make sure that they are in a stable clinical state.

There are several reasons for a false negative test. First of all, subjects can be exposed to the wrong agent [202], or subjects may well have been away from work for too long [203]. If the specific inhalation challenge is negative in the laboratory, provisions should be made to return the subject to his normal workplace while serial monitoring of peak expiratory flow is done. As soon as changes in $\mathrm{PEF}$ or bronchial responsiveness is demonstrated, specific inhalation challenges should be repeated in the laboratory with the appropriate agent.

\subsection{Experimental challenge tests}

Apart from the above standardized tests, a number of relatively new challenging agents have been introduced in research. These are now being used by various laboratories, and are promising approaches for the investigation of specific pathways of pathophysiology of airway narrowing. In view of a potentially wider application of some of these agents in future, the following concise description has been added. It needs to be emphasized that at present none of these challenges have sufficiently been standardized. Therefore, they must be regarded as experimental procedures.

\subsubsection{Adenosine 5'-monophosphate}

Adenosine 5'-monophosphate (AMP) is considered to be an 'indirect' stimulus of airway narrowing, since it exerts its effects through the release of mediators from immunologically activated airway mast cells and probably also through activation of neuronal reflexes [204]. AMP is rapidly metabolised to adenosine, which stimulates several subtypes of purinoceptors. Due to its solubility, AMP enables relatively high doses of adenosine to be given by inhalation in vivo. Asthmatics and atopic nonasthmatic subjects usually respond to AMP with acute airway narrowing, whereas nonatopic normal subjects do not $[205,206]$. Repeated challenges with AMP lead to substantial tachyphylaxis and cross-tachyphylaxis with e.g. exercise. Furthermore, complex interaction with hypertonic saline and allergen challenges has been described.
AMP is increasingly used in testing the involvement of cellular mechanisms in airway hyperresponsiveness [204].

\subsubsection{Leukotrienes}

Leukotrienes are pro-inflammatory metabolites of arachidonic acid through the 5-lipoxygenase pathway. Since the cysteinyl leukotrienes $\left(\mathrm{LTC}_{4}, \mathrm{LTD}_{4}\right.$, and $\left.\mathrm{LTE}_{4}\right)$ are considered to be of major importance in bronchial asthma [207], these agents have been given by inhalation in many research studies. They exert their effects through specific receptors, acting on smooth muscle, endothelial cells, nerve fibres, and secretory cells. Therefore, airway narrowing to these substances has a 'direct' as well as an 'indirect component. Asthmatic subjects are hyperresponsive to leukotrienes, particularly $\mathrm{LTE}_{4}$ [208], and in some studies leukotrienes have been shown to induce transient airway hyperresponsiveness to other stimuli [209, 210]. A highly efficient challenge methodology has been described [210], which has been shown to produce reproducible results [211]. Leukotriene provocation tests are used in pathophysiological research, particularly in testing the increasingly available leukotriene-antagonists or synthesis inhibitors.

\subsubsection{Platelet-activating factor}

Platelet-activating factor (PAF) is also a pro-inflammatory mediator of potential importance in asthma [212]. It acts through various subtype PAF-receptors on inflammatory cells, endothelium, and secretory cells. The acute bronchoconstriction after PAF inhalation might be due to the secondary release of leukotrienes [212]. PAF has been shown to induce airway hyperresponsiveness in normal subjects [213], but this could not be confirmed by other investigators [214]. There is rapid tachyphylaxis to PAF inhalation.

\subsubsection{Bradykinin}

Bradykinin is a potent pro-inflammatory peptide [215] leading to airway narrowing through an 'indirect' mechanism. When given by inhalation, it causes acute bronchoconstriction in asthmatics [216], which is most likely due to smooth muscle contraction, vasodilation, oedema, and/ or airway secretion secondary to stimulation of C-fibre nerve endings and the release of sensory neuropeptides. Therefore, this challenge is currently used to examine the role of axon reflexes under various experimental conditions, e.g. following allergen challenge in asthma [217].

\subsection{5 $\mathrm{SO}_{2}$ and sodium metabisulphite}

$\mathrm{SO}_{2}$ is considered to be a stimulus to investigate the role of cholinergic and/or noncholinergic neural pathways in airway narrowing. Instead of administering gaseous $\mathrm{SO}_{2}[58,218]$ it is much simpler to aerosolize a $\mathrm{SO}_{2}-$ generating solution: sodium metabisulphite [219]. The challenge with this preservative causes acute airway 
narrowing in vivo in a reproducible way [220], and is thereby suitable for research studies. $\mathrm{SO}_{2}$ and metabisulphite challenges may be used to distinguish asthma from COPD [220], but this needs further investigation.

\subsubsection{Tachykinins}

Tachykinins are sensory neuropeptides localized in airway $\mathrm{C}$-fibre nerve endings, which are believed to play a role in bronchial asthma [222]. These pro-inflammatory peptides are released by local axon-reflexes, causing smooth muscle contraction, vasodilation, microvascular leakage, and hypersecretion, through specific NK-receptors [222]. Therefore, tachykinins can be considered to stimulate both «direct» and «indirect» mechanisms of airway narrowing. Among the tachykinins, neurokinin $\mathrm{A}$ and substance $\mathrm{P}$ are being used for inhalation challenge testing in research, either by traditional jet nebulizer [223] or by highły efficient nebulization [224]. Relatively high doses are needed to produce bronchoconstriction in normal subjects, because of endogenous neuropeptide-degrading enzyme activity [224]. In man tachykinins have not been shown to induce subsequent airway hyperresponsiveness to other agents.

\subsubsection{Propranolol}

Another alternative challenging agent is the $\beta$-blocker propranolol. When given by inhalation propranolol induces bronchoconstriction in asthmatic patients but not in normal subjects $[225,226]$. Many patients with COPD do not respond to propranolol $[25,221]$. The mechanism of bronchoconstriction to propranolol is probably related to a blockade of inhibitory $\beta$-receptors on cholinergic nerves. This would enhance acetylcholine release, particularly in asthma, because asthmatics may have impaired function of the inhibitory muscarinic autoreceptors [6]. This mechanism explains the effective reversal of propranolol-induced bronchoconstriction by anticholinergic agents [225, 226]. Since propranolol blocks the effect of $\beta$-adrenergic bronchodilators, anti-cholinergic drugs are an essential component of the safety precautions during this type of challenge.

\section{$4 \quad$ Analysis and interpretation}

\subsection{Dose-response curves: indices and terminology}

The results of bronchoconstrictor challenge tests are preferably analyzed from dose-response curves. This allows calculation of the sensitivity to the stimulus (position of the curve) as well as measurement of the change in severity of the response with increasing dose (slope and maximal response) (figs. 1 and 4) [227]. Unfortunately, not every stimulus can easily be given in a doseresponse way (e.g. exercise), so that under those conditions the analysis should be limited to the time-response curve following a single dose or multiple doses.
The dose-response curve is currently calculated from log-linear dose-response curves, according to in vitro pharmacology. Concentrations can be used instead of doses. In order to allow comparisons between various agents, it is recommended to use molar units. The response (e.g. in $\mathrm{FEV}_{1}$ ) can be expressed in percentage fall from baseline value or from predicted value [227]. Since the complete sigmoid dose-response curve can often not be obtained in vivo, the position of the curve can not be expressed as the most commonly used parameter in vitro: the median effective dose (ED50). Instead, the interpolated provocative dose (PD) or concentration (PC) at a given change in lung function is recommended as an index of sensitivity in vivo (fig. 3) [2]. A decreased PD- or PC-value then indicates the presence of hypersensitivity to the stimulus. In the literature, this term is often regarded as synonymous to the term hyperresponsiveness.

The severity of the response is reflected by the shape of the dose-response curve [227]. This can be expressed as the slope of either the linear mid-part of the curve [228] or of a sigmoid curve fit [229]. A steepening of the slope should be referred to as hyperreactivity [62]. This term should, therefore, not be regarded as being synonymous to hyperresponsiveness. If sigmoid doseresponse curves can be recorded safely (not exceeding $50 \%$ fall in $\mathrm{FEV}_{1}$ in case of normal baseline values), the presence and level of a maximal response plateau provides relevant information on the potential severity of airways obstruction (fig. 1) [3, 42, 227]. The plateau should be calculated by averaging a «stable» response at high doses within a predefined response range [50], or by curve-fitting procedures $[50,229]$. Due to irregularly shaped dose-response curves, these criteria for a maximal response may not always be applicable [230]. An absent or elevated maximal response plateau is an indication of excessive airway narrowing [231], which is associated with asthma symptoms [230]. Measurements of excessive airway narrowing are not recommended in patients with lowered levels of baseline FEV $(\S 2.4 .1)$, except for in specifically designed research protocols under careful guidance of the absolute value of $\mathrm{FEV}_{1}$ during the test [231]. For this reason maximal responses should not be measured for clinical usage, but are important in research studies [3, 227].

Recently, an overall index of position and shape of the dose-response curve in vivo has been introduced for epidemiological purposes by O'Connor et al. [232]. The index is referred to as «dose-response slope» or «twopoint slope», and is obtained by calculation of the slope of the straight line between the origin (\% decline in FEV, post-saline) and the response to the final dose (highest dose or dose giving $>20 \%$ decline in $\mathrm{FEV}_{1}$ ). The slope is obtained by dividing the difference between post-saline and final $\mathrm{FEV}_{1}$ by the highest dose given, and is expressed in \% decline $\mathrm{FEV}_{\text {, }}$ per mol methacholine or histamine. This procedure enables one to measure airway responsiveness quantitatively over the full in vivo range, which may be particularly attractive in epidemiological surveys [233-235]. The usefulness of this index requires further investigation ( $§ 4.3$ ). 


\subsection{Time-response curves}

Even though the early response to allergens or occupational sensitizers can be analyzed in a dose-response way as PD- or PC-value ( $\S 4.1)$, the most common expression of the results is based on time-response curves, as is the case for exercise tests (fig. 5) [14]. Under those conditions, within- and between-subjects comparison can only be made when exactly the same dose of the stimulus has been given. Usually, time-response curves are analyzed by calculating the largest response during a predetermined time-interval. This approach can be applied to both the early and late response. Trapezoidal integration of timeresponses curve gives the area under the curve (AUC), which might be a better alternative that needs to be further evaluated (fig. 6) [169].

\subsection{Reproducibility}

In general, measures of airway responsiveness to histamine and methacholine are reproducible between days when the clinical state of the patient is stable. When repeating challenge tests any potential carry-over effects, such as cumulation, priming, or refractoriness need to be taken into consideration. Reproducibility needs to be calculated according to accepted statistical methods [236239]. It is strongly dependent on the standardization of the protocol, the experience of the technician and the patient, and on the clinical stability of the patient $[46,97$, $99,240,241]$.

When histamine and methacholine inhalation tests, using the tidal breathing and dosimeter methods, are repeated within one week in clinically stable patients, the within-subject standard deviation of $\log \mathrm{PC}_{20}$ or $\log \mathrm{PD}_{20}$ is between 0.09 and 0.33 [83, 85, 92]. Therefore, in hospital populations under optimal conditions, the $95 \%$ confidence interval of $\mathrm{PC}_{20}$ or $\mathrm{PD}_{20}$ based on a single determination is less than one twofold concentration difference. However, these conditions can not always be met, particularly in an epidemiological setting. In those circumstances where the clinical stability of the patients and/or the intertechnician variability can not be controlled, the $95 \%$ confidence interval for single measurements of $\mathrm{PC}_{20}$ or $\mathrm{PD}_{20}$ increases towards $2-3$ twofold dose difference $[46,97,99]$. This also holds for lack of subject's experience [240], and for non-optimally standardized techniques $[90,241]$. When the within-subject variance is related to the between-subject variance in the clinical range $\left(\mathrm{PC}_{20}: 0.3-16 \mathrm{mg} \cdot \mathrm{ml}^{-1}\right)$, the intraclass correlation of the $\mathrm{PC}_{20}$ or $\mathrm{PD}_{20}$ has been reported to be around 0.9 in adults $[19,83,92,98]$. When using the Yan method in children, an intraclass correlation coefficient of 0.78 has been reported [98].

The other variables that can be obtained from the doseresponse curve have not been evaluated extensively on their reproducibility. For instance, the repeatability of the «two-point slope» has been reported to be satisfactory $[98,232]$, although a recent study indicates that it becomes worse in the least responsive subjects in whom the slopes are very shallow [242]. The maximal response plateau has similar reproducibility in clinical [50] and epidemiological studies [230], the $95 \%$ confidence interval of single measurements being about $11 \%$ in adults as well as in children [243].

Less is also known about the reproducibility of the nonpharmacological challenges. The data on cold/dry air inhalation [128], non-isotonic aerosols [125], and exercise $[152,158,244]$ are encouraging, but certainly warrant further studies on the present standardized methodologies. The repeatability of standardized allergen challenges has not formally been investigated. When the level of baseline $\mathrm{FEV}_{1}$, skin test sensitivity and histamine airway responsiveness are not taken into consideration the repeatability of EAR [245, 246] or $\operatorname{LAR}[247,248]$ is disappointing. Howevör, if these pre-test patient characteristics are controlled [167] and the procedure is carefully standardized ( $§ 3.5)$, the EAR and LAR seem to be fairly well reproducible (fig. 6) $[38,164,249]$. Obviously, this needs further investigation.

\subsection{Baseline lung function}

The association between airway responsiveness and baseline airway calibre has long been recognized [250], but the precise mechanisms of this relation have not been determined. Interdependence between these two physiological characteristics might be explained by: (a) geometrical factors determining airway responsiveness, (b) airway responsiveness causing lower levels of baseline lung function, or (c) both variables being commonly dependent on other disease characteristics. These three mechanisms may all be involved, depending on the population of subjects. The association between baseline lung function and airway responsiveness can be observed in cross-sectional analysis in the general population [251]. In clinical populations the association appears to be stronger in COPD than in asthma [25]. Cross-sectional studies in COPD indicate that the level of lung function can account for 24 to $74 \%$ of the variance in airway responsiveness [7]. However, cross-sectional and longitudinal measurements in asthma have indicated that baseline lung function is of minor importance in determining airway responsiveness in this group of patients [252, 253], accounting for about $30 \%$ of the within-subject variance of $\mathrm{PC}_{20}$ [254]. The reverse effect, namely, airway responsiveness causing an accelerated decline in lung function, does seem to play a role in asthma [32] as well as COPD [255].

These findings hamper the interpretation of airway hyperresponsiveness in patients with airways obstruction. On the other hand, they also show that airway responsiveness and baseline lung function are partially independent variables.

\subsection{Clinical relevance of the various challenges}

The choice of the bronchoconstrictor depends on pathophysiological, methodological, and clinical aspects ( $\$ 2.5$ ). Regarding the application in clinical practice, first, airway 
responsiveness measurements can provide useful information in clinical diagnosis $(\$ 2.1)$, particularly in patients without otherwise documented variable airways obstruction $[16,17]$. Airway hyperresponsiveness is not a diagnosis in itself. It is a composite functional disorder, reflecting the potential of variable airways obstruction. The combination of airway hyperresponsiveness and recent symptoms of wheezing (within the previous year) has been advocated as a "gold standard» for defining asthma in epidemiology [256].

Second, changes in airway responsiveness can be used in monitoring treatment effects [35]. In this way it can be shown that bronchodilators can afford an acute protection against bronchoconstrictor stimuli for their duration of action. In research this is often examined using e.g. histamine or methacholine $[231,257]$, but in clinical practice it seems to be more relevant to investigate their protection against physical stimuli, such as exercise or cold air [35]. In particular this holds for the acute effects of sodium cromoglycate and nedocromil [35]. Antiinflammatory drugs like sodium cromoglycate, nedocromil, and particularly inhaled corticosteroids have been shown to reduce airway responsiveness after long-term treatment in asthma [258], but not in patients with COPD in whom it may take substantially longer to reverse airway hyperresponsiveness [259, 260].

When comparing the effects of long-term antiinflammatory treatment on the various challenges, it appears that the induced changes in the position of the doseresponse curve (decrease in sensitivity) differs between pharmacological and physical stimuli [44, 261]. Although changes in the position of curve may not always be the optimal way of expressing protective effects [44], these findings suggest that therapeutical efficacy on airway hyperresponsiveness can not be judged by using one single challenge procedure. Obviously, this needs to be further investigated in combination with other disease characteristics, such as the change in clinical indices and in pathology. Therefore, even though it is clear that longterm therapy can be monitored by airway responsiveness measurements, any superiority of one test over the other is still unclear. Altogether, it can be postulated that airway responsiveness can thus be used as a guide to asthma therapy [26]. However, it still needs to be examined whether adjusting therapy also based on the degree of hyperresponsiveness leads to better prognosis of the disease than therapy according to current international recommendations, based on symptoms and lung function alone $[16,17]$.

This leads to the following general recommendations on choice between the various challenge tests in clinical practice. Histamine and methacholine challenges are first choice in diagnosis and follow-up of patients with asthma. Even though slight differences have been observed between these two agents ( $\S 3.1 .8$ ), they can be used interchangeably in clinical practice. The main indication of these tests is to exclude asthma when spirometry is normal. The clinical relevance of the physical tests is still limited. They do provide information on «indirect» mechanisms of airway narrowing [43], and the results obtained with these tests might be closer associated with clinical disease indices than those obtained with pharmacological tests [262]. Regarding the differential diagnosis between asthma and COPD, non-isotonic aerosols do not allow a clear distinction between these two entities [25, 221]. However, a positive response to isocapnic hyperventilation [136, 263] or exercise [149] seems to be consistent with the diagnosis of asthma. Further application of physical tests consists of the laboratory investigation of the potential protection afforded by anti-asthma drugs [35].

Challenges with allergens and occupational sensitizers should be considered as research tools. Allergen challenge may only have a role in those few cases were immu'notherapy is seriously indicated. Although challenge with occupational sensitizers is considered to be the «gold standard" for the confirmation of occupational asthma [184], these tests are only indicated in case of inconclusive diagnosis based on history, peak expiratory flow and/or histamine responsiveness measurements. These laboratory exposure procedures with sensitizing agents must be restricted to specialized centres.

\subsection{Applications in research}

The measurement of airway responsiveness has a major impact in pathophysiological, clinical, and epidemiological research in patients with asthma or COPD in vivo $[5,6,7]$. Airway hyperresponsiveness may represent a non-invasive indication of various pathological processes in the airway wall [13]. The increase in sensitivity and excessive airway narrowing in response to bronchoconstrictor stimuli are associated with e.g.: epithelial damage, the number and activity of (sub)mucosal inflammatory cells, (non) adrenergical-(non) cholinergical autonomic dysfunction, hyperaemia, plasma exudate, and smooth muscle contractility [3]. The contribution of these mechanisms can be investigated by using various bronchoconstrictor stimuli, either or not combined with specific antagonists or inhibitors of the pathways leading to airway narrowing (see also § 3.7).

One of the best investigational models of airway responsiveness in man in vivo is the induced hyperresponsiveness after exposure to inhaled allergen, occupational sensitizing agents or virus infections [37]. Among these, the allergen-induced hyperresponsiveness following a late asthmatic response has been validated most extensively [264]. This procedure is being widely used in pathophysiological research, and the pharmacological modulation of allergen-induced responses forms a key to the development of anti-asthma drugs. It remains to be established as to whether drug effects on allergen challenges are predictive for their efficacy in clinical asthma.

\section{Conclusions}

Even though methodological issues are not a purpose on their own, they are of vital importance in clinical decision making as well as in science. It is obvious that the present document does not solve all the dilemma's in this 
area. Uncovered and controversial areas still need to be explored. Consequently, improvement and standardization of airway responsiveness measurements should be an ongoing effort. In the following, some of the established issues and a number of remaining questions have been selected.

\subsection{Recommendations}

\subsubsection{General}

- measurements of airwayresponsiveness have a good safety record, provided the procedures are carefully standardized;

- the presently standardized laboratory-protocols are the methods of first choice for pharmacological and physical challenges, as well as for challenges with sensitizing agents; they allow comparison of the results with previous data in the literature;

- the term "nonspecific» airway responsiveness is ambiguous, and should be identified with the challenging agent, since the mechanisms of bronchoconstriction varies between the distinct stimuli;

- hyperresponsiveness should be regarded as an abnormality of airway function, which is associated with various features of inflammation;

- newly developed and potentially better methods should be evaluated on their repeatability and their agreement with currently standardized challenges.

\subsubsection{Clinical usage}

- airway responsiveness measurements with pharmacological agents are particularly useful for the exclusion of asthma in the clinical setting, they are less useful in confirming and distinguishing the diagnoses of asthma and COPD;

- hyperresponsiveness is not synonymous with the diagnosis of asthma, but can provide additional information to clinical symptoms and peak flow measurements on the potential of variable airways obstruction in epidemiological and clinical setting;

- a 10-20\% fall in $\mathrm{FEV}_{1}$ in response to isocapnic hyperventilation or exercise is consistent with the diagnosis of asthma; however, a negative response to these stimuli does not exclude asthma;

- the combination of airway hyperresponsiveness and recent wheezing (in the past year) can be regarded as a definition of asthma for epidemiology;

- in clinical practice histamine and methacholine tests are most extensively validated, and thereby the challenges of first choice in adults; in paediatrics exercise tests can be a better alternative;

- physical challenges (exercise, cold air, non-isotonic aerosols) reflect the involvement of a cascade of «indirect» components of airway narrowing, such as cellular and neurogenic mechanisms;

- inhalation tests with common allergens should be regarded as a research tool;

- challenge tests with occupational sensitizers should only be performed in specialized centres;
- the safety requirements for inhalation challenge tests vary between the different types of stimuli, being most stringent for tests with allergens and occupational sensitizers;

\subsubsection{Materials and methods}

- output should be calibrated for each individual nebulizer; in clinical practice this can be estimated adequately by weighing;

- for research purposes the same nebulizer should be used at exactly the same setting throughout the study;

- thefe are three standardized methods for pharmacological challenges (tidal breathing, dosimeter, and Yan method); the results have similar reproducibility, and the choice between them depends on the type of study (clinical or epidemiological) and local facilities and experience;

- for the tidal breathing method, $2 \mathrm{~min}$ inhalation of doubling doses (nebulizer output $0.13 \mathrm{ml} / \mathrm{min}$ ) is recommended;

- for the dosimeter method, doubling doses should be administered by inhaling 5 puffs of $9 \mu \mathrm{l}$ per dose;

- $\mathrm{FEV}_{1}$ is the lung function index of first choice during challenge tests in clinical practice.

- hypotonic- and hypertonic aerosol challenge should be performed with ultrasonically nebulized distilled water and $4.5 \%$ saline, respectively, with $1.2 \mathrm{ml} \cdot \mathrm{min}^{-1}$ aerosol output and doubling exposure times;

- isocapnic hyperventilation can be performed by doubling steps of minute ventilation with cooled dry air (water content $0 \mathrm{mg} \cdot \mathrm{l}^{-1},-15^{\circ} \mathrm{C}$ ) or dry air at room temperature; alternatively dry air at room temperature can be used at 30,60 , and $100 \%$ of maximal voluntary ventilation;

- during exercise challenge the subject should attain a level of ventilation between $40 \%-60 \%$ of the subjects predicted maximal voluntary ventilation during the last $4 \mathrm{~min}$ of a $6-8 \mathrm{~min}$ test;

- in allergen challenge tests the starting allergen dose is calculated from the histamine or methacholine $\mathrm{PC}_{20}$ and the result of allergen prick skin tests («skin test endpoint»);

- until European consensus about the exposure limits during challenge tests with occupational sensitizers is reached, the American limits (TLV-STEL) are recommended.

\subsubsection{Analysis and interpretation}

when analyzing dose-response curves obtained by inhalation challenge tests, the position of the curve (PC or $\mathrm{PD}$ value) is the index of choice in clinical practice; - the so-called «two-point slope» enables analysis of dose-response curves in the general population, and is a promising index of airway responsiveness in epidemiological studies; its repeatability needs further studies, particularly in adults;

there is a complex interaction between baseline lung function and airway responsiveness, that appears to 
be different between asthma and COPD; therefore, challenge tests are hard to interpret in the presence of airways obstruction.

\subsection{Remaining questions}

- what is the meaning of airway hyperresponsiveness in clinical diagnoses?

- what is the role of airway responsiveness in the clinical follow-up of patients with asthma?

- can airway responsiveness measurements be a guide to asthma therapy?

- what is the meaning of airway hyperresponsiveness in patients with COPD?

- how should the test results or inhaled doses be sizecorrected in children?

- what are the advantages of using physical tests instead of pharmacological tests in clinical practice?

- are monitoring of peak flow and histamine or methacholine challenges true alternatives to challenge with occupational sensitizers in the diagnosis of occupational asthma?

- is an allergen inhalation test an adequate model of clinical asthma in the prediction of treatment effects?

- is maximal bronchoconstriction more relevant than sensitivity as an index of airway responsiveness in clinical practice?

- to what extent do the various tests for hyperresponsiveness relate to the pathology in the airways?

- are physical tests more specific while less sensitive for the diagnosis of asthma?

\section{References}

1. American Thoracic Society. Standards for the diagnosis and care of patients with chronic obstructive pulmonary disease (COPD) and asthma. Am Rev Respir Dis 1987; 136: 225-244. 2. Eiser NM, Kerrebijn KF, Quanjer PhH. - Guidelines for standardization of bronchial challenges with (nonspecific) bronchoconstricting agents. Bull Eur Physiopathol Respir 1983; 19: 495-514.

3. Sterk PJ, Bel EH. - Bronchial hyperresponsiveness: the need for a distinction between hypersensitivity and excessive airway narrowing. Eur Respir $J$ 1989; 2: 267- 274.

4. Holgate ST, Beasley R, Twentyman OP. - The pathogenesis and significance of bronchial hyperresponsiveness in airways disease. Clin Sci 1987; 73: 561-572.

5. Paoletti P, Viegi G, Carrozzi L. - Bronchial hyperresponsiveness, genetic predisposition and environmental factors: importance of epidemiological research. Eur Respir J 1992; 5: 910-912.

6. Bames PJ. - New concepts in the pathogenesis of bronchial responsiveness and asthma. J Allergy Clin Immunol 1989; 83: 1013-1026.

7. O'Connor GT, Sparrow D, Weis ST. - The role of allergy and nonspecific airway hyperresponsiveness in the pathogenesis of chronic obstructive pulmonary disease. Am Rev Respir Dis 1989; 140: 225-252.

8. Djukanovic R, Roche WR, Wilson JW, Beasley CRW, Twentyman OP, Howarth PH, Holgate ST. - Mucosal inflammation in asthma. Am Rev Respir Dis 1990; 142: 434 457.
9. Jeffery PK. - Morphology of the airway wall in asthma and in chronic obstructive pulmonary disease. Am Rev Respir Dis 1991; 143: 1152-1158.

10. Thurlbeck WM. - Pathophysiology of chronic obstructive lung disease. Clin Chest Med 1990; 11: 389-403.

11. Ollerenshaw SL, Woolcock AJ. - Characteristics of the inflammation in biopsies from large airways of subjects with asthma and subjects with chronic airflow limitation. Am Rev Respir Dis 1992; 145: 922-927.

12. Saetta M, Di Stefano A, Maestrelli P, Cisno F, Zamboto F, Calabro S, Potena A, Ciaccia A, Fabbri LM. - Activated $\mathrm{T}$-lymphocytes and macrophages in bronchial mucosa of subjects with chronic bronchitis. Am Rev Respir Dis 1993; 147 301-306.

13. Kerrebijn KF (ed.). - Similarities and discrepancies between asthma and chronic obstructive pulmonary disease. Am Rev Respir Dis 1991; 143: 1149-1196 and 1419-1472.

14. Hargreave FE, Fink JN, Cockcroft DW, Fish JE, Holgate ST, Ramsdale EH, Roberts RS, Shapiro GG, Sheppard D. The role of bronchoprovocation. J Allergy Clin Immunol 1986; 78: $517-524$.

15. Bernstein L (Ed). - Guidelines for clinical investigation of non-bronchodilator anti-asthmatic drugs. J Allergy Clin Immunol 1986; 78: 489-546.

16. Hargreave FE, Dolovich J, Newhouse MT (Ed). - The assessment and treatment of asthma: a conference report. $J$ Allergy Clin Immunol 1990; 85: 1098-1111.

17. National Heart, Lung and Blood Institute, National Institutes of Health Bethesda, Maryland. - International consensus report on diagnosis and treatment of asthma. Eur Respir $J$ 1992; 5: 601-641.

18. Brand PLP, Postma DS, Kerstjens HAM, Koëter GH, and the Dutch CNSLD Study Group. - Relationship of airway hyperresponsiveness to respiratory symptoms and diurnal peak flow variation in patients with obstructive lung disease. Am Rev Respir Dis 1991; 143; 916-921.

19. Higgins BG, Britton JR, Chinn S, Cooper S, Bumey PGJ, Tattersfield AE. - Comparison of bronchial reactivity and peak expiratory flow variability measurements for epidemiologic studies. Am Rev Respir Dis 1992; 145: 588-593.

20. Cockcroft DW, Hargreave FE. - Airway responsiveness. Relevance of random population data to clinical usefulness. Am Rev Respir Dis 1990; 142: 497-500.

21. Britton J. - Is hyperreactivity the same as asthma? Eur Respir J 1988; 1: 478-479.

22. Britton J. - Airway hyperresponsiveness and the clinical diagnosis of asthma: histamine or history. J Allergy Clin Immunol 1992; 89: 19-22.

23. Backer V, Groth S, Dirksen A, Bach-Mortensen N, Hansen KK, Laursen EM, Wendelboe D. - Sensitivity and specificity of the histamine challenge test for the diagnosis of asthma in an unselected sample of children and adolescents. Eur Respir J 1991; 4: 1093-1100.

24. Cockcroft DW, Murdock KY, Berscheid BA, Gore BP. Sensitivity and specificity of histamine $\mathrm{PC}_{20}$ determination in a random selection of young college students. $J$ Allergy Clin Immunol 1992; 89: 23-30.

25. Ramsdale EH, Hargreave FE. - Differences in airway responsiveness in asthma and chronic airflow obstruction. Med Clin North Am 1990; 74: 741-751.

26. Woolcock AJ, Jenkins ChR. - Assessment of bronchial responsiveness as a guide to prognosis and therapy in asthma. Med Clin North Am 1990; 753-765.

27. Josephs LK, Mullee MA, Holgate ST. - Nonspecific bronchial hyperreactivity and its relationship to the clinical expression of asthma. A longitudinal study. Am Rev Respir Dis 1989; 140: 350-357. 
28. Josephs LK, Gregg I, Holgate ST. - Does nonspecific bronchial responsiveness indicate the severity of asthma? Eur Respir J 1990; 3: 220-227.

29. Pham OT, Mur JM, Chau N, Gabiano M, Henquel JC, Teculescu D. - Prognostic value of acetylcholine challenge test: a prospective study. $\mathrm{Br} J$ Ind Med 1984; 41: 267271.

30. Redline S, Tager IB, Segal MR, Gold D, Speizer FE, Weiss ST. - The relationship between longitudinal change in pulmonary function and nonspecific airway responsiveness in children and young adults. Am Rev Respir Dis 1989; 140: 179-184.

31. Gerritsen J, Koëter GH, Postma DS, Schouten JP, Knol K. - Prognosis of asthma from childhood to adulthood. Am Rev Respir Dis 1989; 140: 1325-1330.

32. Van Schayck CP, Dompeling E, van Herwaarden CLA, Wever AMJ, van Weel Ch. - Interacting effects of atopy and bronchial hyperresponsiveness on the annual decline in lung function and the exacerbation rate in asthma. Am Rev Respir Dis 1991; 144: 1297-1301.

33. Quanjer PhH, Tammeling GJ, Cotes JE, Pedersen OF, Peslin R. - Lung volumes and forced ventilatory flows. Eur Respir J 1993; 6 (Suppl. 16): 4-39.

34. Malo J-L, Fu LY, L'Archevêque J, Ghezzo J, Cartier A. - Duration of the effect of astimizole on histamine-inhalation tests. J Allergy Clin Immunol 1990; 85: 729-736.

35. Cockcroft DW. - Airway hyperresponsiveness: therapeutic implications. Ann Allergy 1987; 59: 405-414.

36. Vathenen AS, Knox AJ, Wisnewski A, Tattersfield AE. - Time course of change in bronchial reactivity with an inhaled corticosteroid in asthma. Am Rev Respir Dis 1991; 143: 1317-1321.

37. Cockcroft DW. - Modulation of airway hyperresponsiveness. Ann Allergy 1988; 60: 465-471.

38. O'Byme PM, Dolovich J, Hargreave FE. - Late asthmatic responses. Am Rev Respir Dis 1987; 136: 740-751.

39. Neville E, Gribbin H, Harrison BDW. - Acute severe asthma. Respir Med 1991; 85: 463-474.

40. Merkus PJFM, Eelkman Rooda HM, van Essen-Zandvliet EEM, Duiverman EJ, Quanjer PhH, Kerrebijn KF. - Assessment of bronchodilatation after spontaneous recovery from a histamine challenge in asthmatic children. Thorax 1992; 47: 355-359.

41. Moreno RH, Hogg JC, Paré PD. - Mechanics of airway narrowing. Am Rev Respir Dis 1986; 133: 1171-1180.

42. Macklem PT. - A hypothesis linking bronchial hyperreactivity and airway inflammation: implications for therapy. Ann Allergy 1990; 64: 113-116.

43. Pauwels R, Joos G, van der Straeten M. - Bronchial hyperresponsiveness is not bronchial responsiveness is not bronchial asthma. Clin Allergy 1988; 18: 317-321.

44. Vathenen AS, Knox AJ, Wisniewski A, Tattersfield AE. - Effect of budesonide on bronchial reactivity to histamine, exercise, and eucapnic dry air hyperventilation in patients with asthma. Thorax 1991; 46: 811-816.

45. Pliss LB, Ingenito EP, Ingram RH. - Responsiveness, inflammation, and effects of deep breaths on obstruction in mild asthma. J Appl Physiol 1989; 66: 2298-2304.

46. Dehaut P, Rachielle A, Martin RR, Malo JL. Histamine dose-response curves in asthma: reproducibility and sensitivity of different indices to assess response. Thorax 1983; 38: $516-522$.

47. Gibbons W, Macklem PT. - Analysis of bronchial doseresponse (BDR) curves in terms of maximal bronchoconstriction. Am Rev Respir Dis 1992; 145: A733.

48. Quanjer $\mathrm{PhH}$ (ed). - Standardized lung function testing. Bull Eur Physiopathol Respir 1983; 19 (Suppl 5): 1-95.
49. Zamel N. - Partial flow-volume curves. Bull Eur Physiopathol Respir 1984; 20: 471-475.

50. Sterk PJ, Daniel EE, Zamel N, Hargreave FE. - Limited bronchoconstriction to methacholine using partial flow-volume curves in nonasthmatic subjects. Am Rev Respir Dis 1985; 132: 272-277.

51. Killian KJ. - Assessment of dyspnoea. Eur Respir J 1988; 1: 195-197.

52. Burdon JGW, Juniper EF, Killian KJ, Hargreave FE, Campbell EJM. - The perception of breathlessness in asthma. Am Rev Respir Dis 1982; 126; 825-828.

53. Turcotte H, Corbeil F, Boulet L-Ph. - Perception of breathlessness during bronchoconstriction induced by antigen, exercise, and histamine challenges. Thorax 1990; 45: 914 918.

54. Stark RD. \- Dyspnoea: assessment and pharmacological manipulation. Eur Respir J 1988; 1: 280-287.

55. Dautrebande L, Philippot E. - Crise d'asthme expérimental par aérosols de carbaminoylcholine chez l'homme, traitée par dispersat de phénylaminopropane. Étude de l'action sur la respiration de ces substances par la détermination du volume respiratoire utile. Presse Méd 1941; 49: 942-946.

56. Tiffeneau R, Beauvallet M. - Épreuve de bronchoconstriction et de bronchodilatation par aérosols. Emploi pour le dépistage, la mesure et le contrôle des insuffisances respiratoires chroniques. Bull Acad Nat Med 1945; 129: 165-168.

57. Curry JJ. - The action of histamine on the respiratory tract in normal and asthmatic subjects. $J$ Clin Invest 1946; 25: 785-791.

58. De Vries K, Booij-Noord H, Van der Lende R, Van Lookeren Campagne JG, Orie NGM. - Reactivity of the bronchial tree to different stimuli. Les Bronches 1968; 18: 439542.

59. Orehek J, Gayrard P. - Les tests de provocation bronchique non-spécifiques dans l'asthme. Bull Eur Physiopathol Respir 1976; 12: 565-598.

60. Hargreave FE, Ryan G, Thomson NC, O' Byme PM, Latimer K, Juniper EF, Dolovich J. - Bronchial responsiveness to histamine or methacholine in asthma: measurement and clinical significance. I Allergy Clin Immunol 1981; 68: 347355.

61. White MV, Slater JE, Kaliner MA. - Histamine and asthma. Am Rev Respir Dis 1987; 135: 1165-1176.

62. Orehek J, Gayrard P, Smith AP, Grimaud C, Charpin J. - Airway response to carbachol in normal and asthmatic subjects. Distinction between bronchial sensitivity and reactivity. Am Rev Respir Dis 1977; 115: 937-943.

63. Cockcroft DW, Berscheid BA. - Effect of pH on bronchial response to histamine. Thorax 1982; 87: 133-136.

64. Brand PLP, Kerstjens HAM, Postma DA, Sterk PJ, Quanjer PhH, Sluiter HJ, Dijkman JH, Van Herwaarden CLA, Hilvering C, Jansen HM, Koëter GH, Kreukniet J, and the Dutch CNSLD Study Group. - Long-term multi-centre trial in chronic nonspecific lung disease: methodology and baseline assessment in adult patients. Eur Respir $J$ 1992; 5: 21-31. 65. Rosenfeld J, Juniper EF, Hargreave FE. - Gas chromatographic determination of methylcholine in pharmaceutical preparations. J Chromotog 1984; 287: 433-437.

66. Alberts WM, Ferguson PR, Ramsdell JW. - Preparation and handling of methacholine chloride solutions: effect of hygroscopic properties of methacholine. Am Rev Respir Dis 1983; 127: 350-351.

67. Sont JK, Kraus JJAM, Bel EH, Sterk PJ. - Inhalation challenge tests with methacholine chloride and -bromide are interchangeable in normal and asthmatic subjects. Eur Respir $J$ 1989; 2 (suppl 5): 302S.

68. Marwaha RK, Johnson BF. - Long-term stability study 
of histamine in sterile bronchoprovocation solutions. Am J Hosp Pharm 1986; 43: 380-383.

69. Nielsen NH, Madsen F, Frölund L, Svendsen UG, Weeke B. - Stability of histamine dihydrochloride in solution. Allergy 1988; 43: 454-457.

70. Pratter MR, Marwaha RK, Irwin RS, Johnson BF, Curley FJ. - Stability of stored histamine di-phosphate solutions. Clinically useful information. Am Rev Respir Dis 1985; 132: 1130-1131.

71. Pratter MR, Woodman TF, Irwin RS, Johnson B. Stability of stored methacholine chloride solutions. Clinically useful information. Am Rev Respir Dis 1982; 126: 717-719.

72. Kongerud J, Soyseth V, Johansen B. - Room temperature influences output from the Wright jet nebulizer. Eur Respir J 1989; 2: 681-684.

73. Summers QA. - Inhaled drugs and the lung. Clin Exp Allergy 1991; 21: 259-268.

74. Sterk PJ, Plomp A, Van de Vate JF, Quanjer PhH. Physical properties of aerosols produced by several jet and ultrasonic nebulizers. Bull Eur Physiopathol Respir 1984; 20: 65-72.

75. Le Souëf PN. - Validity of methods used to test airway responsiveness in children. Lancet 1992; 339: 1282-1284.

76. Madsen F, Nielsen NH, Frölund L, Svendsen UG, Weeke B. - Bronchial challenge: a small reservoir for the Wright jet-nebulizer. Bull Eur Physiopathol Respir 1987; 23: 67-71.

77. Dennis JH, Stenton SC, Beach JR, Avery AJ, Walters EH, Hendrick DJ. - Jet and ultrasonic nebulizer output. Use of a new method for direct measurement of aerosol output. Thorax 1990; 45: 728-732.

78. Merkus PJFM, van Essen-Zandvliet EEM, Parlevliet E, Borsboom G, Sterk PJ, Kerrebijn KF, Quanjer PhH. Changes of nebulizer output over the years. Eur Respir J 1992; 5: 488-491.

79. Ryan G, Dolovich MB, Obminski G, Cockcroft DW, Juniper EF, Hargreave FE, Newhouse MT. - Standardization of inhalation provocation tests: influence of nebulizer output, particle size and method of inhalation. J Allergy Clin Immunol 1981; 67: 156-161.

80. Sterk PJ, Plomp A, Crobach MJJS, Van de Vate JF, Quanjer PhH. - The physical properties of a jet nebulizer and their relevance for the histamine provocation test. Bull Eur Physiopathol Respir 1983; 19: 27-36.

81. Cockcroft DW, Hurst TS, Gore BP. - Importance of evaporative water losses during standardized nebulized inhalation provocation tests. Chest 1989; 96: 505-508.

82. Cockcroft DW, Killian DN, Mellon JJA, Hargreave FE. - Bronchial reactivity to inhaled histamine: a method and clinical survey. Clin Allergy 1977; 7: 235-243.

83. Juniper EF, Frith PA, Dunnett C, Cockcroft DW, Hargreave FE. - Reproducibility and comparison of responses to inhaled histamine and methacholine. Thorax 1978; 33: 705710.

84. Juniper EF, Cockcroft DW, Hargreave FE. - Histamine and methacholine inhalation tests: tidal breathing method. Laboratory procedure and standardisation. $\mathrm{AB}$ Draco, Lund, Sweden; 1991.

85. Juniper EF, Syty-Golda M, Hargreave FE. - Histamine inhalation tests: inhalation via a face mask versus a valve box with mouthpiece. Thorax 1984; 39: 556-557.

86. Cartier A, Malo J-L, Bégin P, Sestier M, Martin RR. Time course of the bronchoconstriction induced by inhaled histamine and methacholine. J Appl Physiol 1983; 54: 821-826.

87. Juniper EF, Frith PA, Hargreave FE. - Airway responsiveness to histamine and methacholine: relationship to minimum treatment to control symptoms of asthma. Thorax 1981; 36: $575-579$.
88. Cockcroft DW, Berscheid BA. - Standardization of inhalation provocation tests: dose vs concentration of histamine. Chest 1982; 82: 572-575.

89. Albronda B, Wijkstra P, Gimeno F, van Altena R, Kremer AM, deMonchy JGR. - Repeatability of the $30 \mathrm{sec}$ histamine challenge test and comparison with the 2 min method. Am Rev Respir Dis 1992; 145 (4 suppl): A732.

90. Chai H, Farr RS, Froehlich LA, Mathison DA, McLean JA, Rosenthal RR, Sheffer AL, Spector SL, Townley RG. Standardization of bronchial inhalation challenge procedures. $J$ Allergy Clin Immunol 1975; 56: 323-327.

91. Hendrick DJ, Fabbri LM, Hughes JM, Banks DE, Barkmant HW, Connolly MJ, Jones RN, Weill H. - Modification of the methacholine inhalation tests and its epidemiologic use in polyurethane workers. Am Rev Respir Dis 1986; 133: 600-604

92. Ryan G, Dolovich MB, Roberts RS, Frith PA, Juniper EF, Hargreave FE, Newhouse MT. - Standardization of inhalation provocation tests: two techniques of aerosol generation and inhalation compared. Am Rev Respir Dis 1981; 123: 195-199. 93. Birnie, D Schatzenberg GWS, Hop WCJ, van EssenZandvliet EEM, Kerrebijn KF. - Does the outcome of the tidal breathing and dosimeter methods of assessing bronchial responsiveness in children with asthma depend on age? Thorax 1990; 45: 199-202.

94. Yan K, Salome C, Woolcock AJ. - Rapid method for measurement of bronchial responsiveness. Thorax 1983; 38: 5561.

95. Bennett JB, Davies RJ. - A comparison of histamine and methacholine bronchial challenges using the DeVilbiss 646 nebulizer and the Rosenthal-French dosimeter. $\mathrm{Br} J$ Dis Chest 1987; 81: 252-259.

96. Nieminen MM, Ladensu A, Kellomaeki L, Karvonen J, Muittari A. - Methacholine bronchial challenge using a dosimeter with controlled breathing. Thorax 1988; 43: 896-900. 97. Chinn S, Britton JR, Burney PGJ, Tattersfield AE, Papacosta AO. - Estimation and repeatability of the response to inhaled histamine in a community survey. Thorax 1987; 42 : 45-52.

98. Peat JK, Salome CM, Bauman A, Toelle BG, Wachinger SL, Woolcock AJ. - Repeatability of histamine bronchial challenge and comparability with methacholine bronchial challenge in a population of Australian schoolchildren. Am Rev Respir Dis 1991; 144: 338-343.187.

99. Britton J, Mortagy A, Tattersfield AE. - Histamine challenge testing: comparison of three methods. Thorax 1986; 41: 128-132.

100. DuToit J, Woolcock AJ, Salome CM, Sundrum R, Black JL. - Characteristics of bronchial hyperresponsiveness in smokers with chronic airflow limitation. Am Rev Respir Dis 1986; 134: 498-501.

101. Manning PJ, Jones GL, O'Byme PM. - Tachyphylaxis to inhaled histamine in asthmatic subjects. J Appl Physiol 1987; 63: 1572-1577.

102. Beckett WS, McDonnell WF, Wond ND. - Tolerance to methacholine inhalation challenge in nonasthmatic subjects. Am Rev Respir Dis 1988; 137: 1499-1501.

103. Stevens WH, Manning PJ, Watson RM, O'Byme PM. Tachyphylaxis to inhaled methacholine in normal but not asthmatic subjects. J Appl Physiol 1990; 69: 875-879.

104. Allegra L, Bianco S. - Non-specific bronchoreactivity obtained with an ultrasonic aerosol of distilled water. Eur $J$ Respir Dis 1980; 61: 41-49.

105. Schoeffel RE, Anderson SD, Altounyan REC. - Bronchial hyperreactivity in response to inhalation of ultrasonically nebulised solutions of distilled water and saline. Brit Med J 1981; 283: 1285-1287. 
106. Smith CM, Anderson SD. - Inhalation provocation tests using non-isotonic aerosols. J Allergy Clin Immunol 1989; 84: 781-790.

107. Belcher NG, Lee TH, Rees PJ. - Airway responses to hypertonic saline, exercise and histamine challenges in bronchial asthma. Eur Respir J 1989; 2: 4448.

108. Boulet LP, Legris C, Thibault L, Turcotte H. Comparative bronchial responses to hyperosmolar saline and methacholine in asthma. Thorax 1987; 42: 953-958.

109. Finnerty JP, Holgate ST. - Evidence for the roles of histamine and prostaglandins as mediators in exercise-induced asthma: the inhibitory effect of terfenadine and flurbiprofen alone and in combinations. Eur Respir J 1990; 3: 540-547.

110. Gravelyn TR, Pan PM, Eschenbacher WL. - Mediator release in an isolated segment in subjects with asthma. Am Rev Respir Dis 1988; 137: 641-646.

111. Finney MJB, Anderson SD, Black JL. - Terfenadine modifies airway narrowing induced by the inhalation of nonisotonic aerosols in subjects with asthma. Am Rev Respir Dis 1990; 141: 1151-1157.

112. Rodwell LT, Anderson SD, Seale JP. - Inhaled clemastine, an $\mathrm{HI}$ antihistamine inhibits airway narrowing caused by aerosols of non-isotonic saline. Eur Respir J 1991; 4: 1126-1134.

113. Umeno E, McDonald DM, Nadel JA. - Hypertonic saline increases vascular permeability in the rat trachea by producing neurogenic inflammation. $J$ Clin Invest, 1990; 85: 1905-1908.

114. Anderson SD, Schoeffel RE, Finney M. - Evaluation of ultrasonically nebulised solutions as a provocation in patients with asthma. Thorax 1983; 38: 284-291.

115. Rodwell LT, DuToit JI, Anderson SD, Seale JP. Nedocromil sodium (NS) inhibits the airway response to challenge with hyperosmolar aerosols in asthmatic subjects. Eur Respir J 1991; 4: 545S.

116. Robuschi M, Gambaro G, Spagnotto S, Vaghi A, Bianco S. - Inhaled furosemide is highly effective in preventing ultrasonically nebulised water bronchoconstriction. Pulm Pharmacol 1989; 1: 187-191.

117. Rodwell LT, DuToit JI, Anderson SD, Seale JP. Inhaled furosemide inhibits the airway response to challenge with $4.5 \% \mathrm{NaCl}$ aerosol in asthmatic subjects. Thoracic Society of Australia \& New Zealand. 1992 Annual Scientific Conference; p 42.

118. Fabbri LM, Hendrick DJ, Diem JE. - Effect of atropine on the bronchial response of asthmatic subjects to the inhalation of ultrasonically nebulised distilled water. $J$ Allergy Clin Immunol 1983; 71: 468-472.

119. Boulet L-P, Turcotte H, Tennina S. - Comparative efficacy of salbutamol, ipratropium, and cromoglycate in the prevention of bronchospasm induced by exercise and hyperosmolar challenges. J Allergy Clin Immunol 1989; 83: 882-887. 120. Rodwell LT, Anderson SD, Seale JP. - Inhaled steroids modify bronchial responsiveness to hypermolar saline. Eur Respir J 1992; 5: 953-962.

121. Gibson PG, Saltos N, Hopkins YJ, Borgas T. - Repair of airway inflammation in asthma: The role of mast cells in persisting airway hyperresponsiveness. Thoracic Society of Australia \& New Zealand. 1992 Annual Scientific Conference; p 46.

122. Higenbottam T, Jackson M, Rashdi T, Stewart S, Coutts C, Wallwork J. - Lung rejection and bronchial hyperresponsiveness to methacholine and ultrasonically nebulized distilled water in heart-lung transplantation patients. Am Rev Respir Dis 1989; 140: 52-57.

123. Anderson SD, Smith CM. - The use of nonisotonic aerosols for evaluating bronchial hyperresponsiveness. In:
Provocative Challenge Procedures. Spector SL (Ed). Futura Publishing Company Inc, Mount Kisco, NY 1989; pp 227-252. 124. Anderson SD. - Bronchial challenge by ultrasonically nebulized aerosols. Clin Rev Allergy 1985; 3: 427-439.

125. Smith CM, Anderson SD. - Inhalational challenge using hypertonic saline in asthmatic subjects: a comparison with responses to hyperpnoea, methacholine and water. Eur Respir $J$ 1990; 3: 144-151.

126. Galdes-Sebalt M, McLaughton FJ, Levison H. Comparison of cold air, ultrasonic mist and methacholine inhalations as tests of bronchial reactivity in normal and asthmatic children. J Pediatr 1985; 107: 526-530.

127. Herxheimer H. - Hyperventilation asthma. Lancet 1946; i: $83-87$.

128. O'Byme PM, Ryan G, Morris M, McCormack D, Jones NL, Morse JLC, Hargreave FE. - Asthma induced by cold air and its relation to nonspecific bronchial responsiveness to methacholine. Am Rev Respir Dis 1982; 125: 281-285.

129. Heaton RW, Henderson AF, Costello JF. - Cold air as a bronchial provocation technique. Reproducibility and comparison with histamine and methacholine inhalation. Chest 1984; 86: $810-814$.

130. Tessier P, Ghezzo H, L'Archevêque J, Cartier A, Malo JL. - Shape of the dose-response curve to cold air inhalation in normal and asthmatic subjects. Am Rev Respir Dis 1987; 136: $1418-1423$.

131. Freed AN, Fuller SD, Stream CE. - Transient airway cooling modulates dry-air-induced and hypertonic aerosolinduced bronchoconstriction. Am Rev Respir Dis 1991; 144: 358-362.

132. Malo JL, Cartier A, L'Archevêque, Ghezzo H, Martin RR. - Cold air inhalation has a cumulative bronchospastic effect when inhaled in consecutive doses for progressively increasing degrees of ventilation. Am Rev Respir Dis 1986; 134: 990-993. 133. Phillips YY, Jaeger JJ, Laube BL, Rosenthal RR. Eucapnic voluntary hyperventilation of compressed gas mixtures. Am Rev Respir Dis 1985; 131: 31-35.

134. Zach M, Polgar G, Kump H, Kroisel P. - Cold air challenge in the diagnosis of asthma in children: Practical application and theoretical aspects. Paediatrics 1984; 18: 469 478.

135. Chandler-Deal E Jr, McFadden ER Jr, Ingram RH Jr, Breslin FJ, Jaegar JJ. - Airways responsiveness to cold air and hyperventilation in normal subjects and in those with hay fever and asthma. Am Rev Respir Dis 1980; 121: 621-628. 136. Decramer M, Demedts M, van de Woestijne KP. Isocapnic hyperventilation with cold air in healthy non smokers, smokers and asthmatic subjects. Bull Eur Physiopathol Respir 1984; 20: 237-243.

137. Jones RS, Wharton MJ, Buston MH. - The place of physical exercise and bronchodilator drugs in the assessment of the asthmatic child. Arch Dis Childh 1963; 38: 539-545. 138. Anderson SD, Silverman M, Godfrey S, Konig P. Exercise-induced asthma: A review. Br J Dis Chest 1975; 69: $1-39$.

139. Deal EC, McFadden ER, Ingram RH, Jaeger JJ. Hyperpnoea and heat flux: initial reaction sequence in exerciseinduced asthma. J Appl Physiol 1979; 46: 476-483.

140. Chen WY, Horton DJ. - Heat and water loss from the airways and exercise-induced asthma. Respiration 1977; 34: 305-313.

141. McFadden ER, Ingram RH. - Exercise-induced asthma: observations on the initiating stimulus. N Engl J Med 1979; 301: 763-769.

142. Anderson SD. - Is there a unifying hypothesis for exercise-induced asthma. J Allergy Clin Immunol 1984; 73: $660-665$. 
143. Eggleston PA, Kagey-Sobotka A, Lichtenstein LM. - A comparison of the osmotic activation of basophils and human lung mast cells. Am Rev Respir Dis 1987; 135: 1043-1048. 144. McFadden ER. - Hypothesis: exercise-induced asthma as a vascular phenomenon. Lancet 1990; 1: 880-882.

145. Gilbert IA, McFadden ER. - Airway cooling and rewarming. The second reaction sequence in exercise-induced asthma. J Clin Invest 1992; 90: 699-704.

146. Anderson SD, Daviskas E. - The airway microvasculature and exercise-induced asthma. Thorax 1992; 47: 748752.

147. Clough JB, Hutchinson SA, Williams JD, Holgate ST. Airway response to exercise and methacholine in children with respiratory symptoms. Arch Dis Childh 1991; 66: 579583.

148. Eliasson AH, Phillips YY, Rajagopal KR, Howard RS. Sensitivity and specificity of bronchial provocation testing. An evaluation of four techniques in exercise induced bronchospasm. Chest 1992; 102: 347-355.

149. Godfrey S, Springer C, Novski N, Maayan Ch, Avital A. - Exercise but not methacholine differentiates asthma from chronic lung disease in children. Thorax 1991; 46: 488-492. 150. Backer V, Ulrik CS. - Bronchial responsiveness to exercise in a random sample of 494 children and adolescents from Copenhagen. Clin Exp Allergy 1992; 22: 741-747.

151. Burr ML, Butland BK, King S, Vaughan-Williams E. Changes in asthma prevalence: two surveys 15 years apart. Arch Dis Childh 1989; 64: 1452-1456.

152. Anderson SD. - Exercise-induced asthma. In: Allergy: Principles and Practice. Fourth Edition. Middleton E, Reed CE, Ellis EF, Franklin Adkinson N, Yunginger JW (Eds). The CV Mosby Company 1993 (in press).

153. Lee TH, O'Hickey SP. - Exercise-induced asthma and late phase reactions. Eur Respir J 1989; 2: 195-197.

154. Karjalainen J. - Exercise response in young men with asthma: no evidence for a late asthmatic reaction. Thorax 1991; 46: $100-104$.

155. Tullett WM, Tan KM, Wall RT, Patel KR. - Doseresponse effect of sodium cromoglycate pressurized aerosol in exercise-induced asthma. Thorax 1985; 40: 41-44.

156. Anderson SD. - Methodology for identifying and assessing exercise-induced asthma. In: Bronchial Provocation Tests. Fish J, Hargreave FE (Eds). Marcel Dekker 1993 (in press).

157. Woolley M, Anderson SD, Quigley BM. - Duration of protective effect of terbutaline sulphate and cromolyn sodium a combination on exercise-induced asthma. Chest 1990; 97: 3945.

158. Anderson SD, Rodwell LT, DuToit J, Young IH. Duration of protection of inhaled salmeterol in exercise-induced asthma. Chest 1991; 100: 1254-1260.

159. Anderson SD. - Diagnosis and management of exerciseinduced asthma. In: Bronchial Asthma: Principles of Diagnosis and Practice. Gershwin ME, Halpern GM (Eds). Humana Press Inc 1992 (in press).

160. Cockcroft DW. - Bronchial inhalation tests II. Ann Allergy 1987; 59: 89-99.

161. Durham SR, Craddock CF, Cookson WO, Benson MK. Increases in airway responsiveness to histamine precede allergen-induced late asthmatic responses. $J$ Allergy Clin Immunol 1988; 82: 764-770.

162. Cockcroft DW, Ruffin RE, Dolovich J, Hargreave FE. Allergen-induced increase in nonallergic bronchial reactivity. Clin Allergy 1977; 7: 503-513.

163. Cartier A, Thomson NC, Frith PA, Roberts R, Hargreave FE. - Allergen-induced increase in bronchial responsiveness to histamine: relationship to the late asthmatic response and change in airway calibre. $J$ Allergy Clin Immunol 1982; 70: 170-177.

164. Cockcroft DW, Murdock KY. - Comparative effects of inhaled salbutamol, sodium cromoglycate and beclomethasone dipropionate on allergen-induced early asthmatic responses, late asthmatic responses and increased bronchial responsiveness to histamine. J Allergy Clin Immunol 1987; 79: 734-740.

165. Kirby JG, Hargreave FE, Cockcroft DW, O'Byrne PM. Indomethacin inhibits allergen-induced airway hyperresponsiveness but not allergen-induced asthmatic responses. $J$ Appl Physiol 1989; 66: 578-583.

166. Melillo G, Aas K, Cartier A, Davies RJ, Debelic M, Dreborg S, Kerrebijn KF, Lassen A, Pinto Mendes J, Rizzo A, Rosenthal RR, Tateishi S, Coosico R. - Guidelines for the standardization of bronchial provocation tests with allergens. Allergy 1991; 46: 321-329.

167. Cockcroft DW, Murdock KY, Kirby J, Hargreave FE. Prediction of airway responsiveness to allergen from skin sensitivity to allergen and airway responsiveness to histamine. Am Rev Respir Dis 1987; 135: 264-267.

168. Frölund L, Madsen F, Scharling B, Heinig JH, Svendsen UG. - Bronchial allergen challenge: dose versus concentration. Clin Exp Allergy 1992; 22: 219-225.

169. Aalbers R, Kauffman HF, Koëter GH, Postma DS, de Vries K, de Monchy GJR. - Dissimilarity in methacholine and adenosine 5 '-monophosphate responsiveness 3 and 24 hours after allergen challenge. Am Rev Respir Dis 1991; 144: 352357.

170. Chan-Yeung M, Lam S. - Occupational asthma. Am Rev Respir Dis 1986; 133: 686-803.

171. Chan-Yeung M. - Occupational asthma. Chest 1990; 98 (Suppl): 148s-161s.

172. Pauli G, Bessot JC, Dietemann-Molard A. - Occupational asthma: investigations and aetiological factors. Bull Eur Physiopathol Respir 1986; 22: 399-426.

173. Brooks SM, Weiss MA, Bernstein IL. - Reactive airways dysfunction syndrome (RADS). Persistent asthma syndrome after high-level irritant exposure. Chest 1985; 86: 376-384.

174. Boulet LP. - Increases in airway responsiveness following acute exposure to respiratory irritants. Reactive airway dysfunction syndrome or occupational asthma. Chest 1988; 94: 476-481.

175. Tarlo SM, Broder I. - Irritant-induced occupational asthma. Chest 1989; 96: 297-300.

176. Coté J, Kennedy S, Chan-Yeung M. - Sensitivity and specificity of $\mathrm{PC}_{20}$ and PEFR in cedar asthma. $J$ Allergy Clin Immunol 1990; 85: 592-598.

177. Perrin B, Lagier J, L'Archevêque J et al. - Occupational asthma: validity of monitoring of peak expiratory flow rates and non-allergic bronchial responsiveness as compared to specific inhalation challenges. Eur Respir $J$ 1992; 5: 40-48.

178. Vedal S, Enarson DA, Chan H, Ochnio J, Tse KS, ChanYeung M. - A longitudinal study of the occurrence of bronchial hyperresponsiveness in western red cedar workers. Am Rev Respir Dis 1988; 137: 651-655.

179. Mapp CE, Chiesura-Corona P, De Marzo N, Fabbri LM. - Persistent asthma due to isocyanates. A follow-up study of subjects with occupational asthma due to toluene diisocyanate (TDI). Am Rev Respir Dis 1988; 137: 1326-1329.

180. Hargreave FE, Ramsdale EH, Pugsly SO. - Occupational asthma without bronchial hyperresponsiveness. Am Rev Respir Dis 1984; 130: 513-515.

181. Mapp CE, Dal Vecchio L, Boschetto P, De Marzo N, Fabbri LM. - Toluene diisocyanate-induced asthma without airway hyperresponsiveness. Eur J Respir Dis 1986; 68: 8995. 
182. Pepys J, Hutchcroft BJ. - Bronchial provocation tests in etiologic diagnosis and analysis of asthma. Am Rev Respir Dis 1975 ; 112: 829-859.

183. Cartier A, Bernstein IL, Sherwood Burge P, Cohn JR, Fabbri LM, Hargreave FE, et al. - Guidelines for bronchoprovocation on the investigation of occupational asthma. Report of the Subcommittee on bronchoprovocation for occupational asthma. J Allergy Clin Immunol 1989; 84: 823-829.

184. Malo JL, Cartier A. Asthma in the workplace. In: Bernstein LI, Chan-Yeung M, Malo JL, Bernstein DI, (Eds). Occupational Asthma. Marcel Dekker, New York - Basle 1992; in press.

185. Mapp CE, Di Giacomo R, Broseghini C, et al. - Late, but not early, asthmatic reactions induced by toluene diisocyanate (TDI) are associated with increased airway responsiveness. Eur J Respir Dis 1986; 69: 276-284.

186. Tossin L, Chiesura-Corona P, Fabbri LM, et al. Ketotifen does not inhibit asthmatic reactions induced by toluene-diisocyanate in sensitized subjects. Clin Exp Allergy 1989; 19: 177-182.

187. American Conference of Governmental Industrial Hygienists (ACGIH). Threshold limit values for chemical substances and biological exposure indices. ACGIH, 6500 Cincinnati, OH USA 1992.

188. Cloutier Y, Lagier F, Lemieux R et al. - New methodology for specific inhalation challenges with occupational agents in powder form. Eur Respir J 1989; 2: 769-777.

189. Cloutier Y, Malo JL. - Update on an exposure system for particles in the diagnosis of occupational asthma. Eur Respir $J$ 1992; 5: 887-890.

190. Cloutier Y, Lagier F, Cartier A, Malo J-L. - Validation of an exposure system to particles for the diagnosis of occupational asthma. Chest, 1992; 102: 402-407.

191. Butcher BT. - Inhalation challenge testing with toluene diisocyanate. J Allergy Clin Immunol 1979; 64: 655-657.

192. McCormack DA, Hepperle M, Hargreave FE. - Design of a remotely operated static flow exposure chamber for isocyanate exposure tests. J Allergy Clin Immunol 1989; 83: 172 (Abstract)

193. Hammad YY, Rando RJ, Abdel-Kader H. - Considerations in the design and use of human inhalation challenge delivery system. Folia Allergol Immunol 1985; 32: 37-44.

194. Vandenplas O, Malo JL, Cartier A, Perrealt G, Cloutier I. - Closed-circuit methodology for inhalation challenge tests with isocyanates. Am Rev Respir Dis 1992; 145: 582-587.

195. Mapp CE, Boschetto P, Dal Vecchio L, Maestrelli P. Fabbri LM. - Occupational asthma due to isocyanates. Eur Respir J 1988; 1: 273-279.

196. Bérubé D, Cartier A, L'Archevêque J, Ghezzo H, Malo JL. - Comparison of peak expiratory flow rates and FEV in assessing bronchomotor tone after challenges with occupational sensitizers. Chest 1991; 99: 831-836.

197. Cartier A, Thomson N, Frith P, Roberts R, Hargreave F. - Allergen-induced increase in bronchial responsiveness to histamine: relationship to the late asthmatic response and change in airway calibre. J Allergy Clin Immunol 1982; 7: 170 177.

198. Malo JL, L'Archevêque J, Cartier A. - Significant changes in nonspecific bronchospastic reactions caused by isocyanates but not after a late reaction caused by plicatic acid. J Allergy Clin Immunol 1989; 83: 159-165.

199. Lam S, Tan F, Chan H, Chan-Yeung M. - Relationship between types of asthmatic reaction, nonspecific bronchial reactivity and specific IgE antibodies in patients with red cedar asthma. J Allergy Clin Immunol 1983; 72: 134-139.

200. Cartier A, L'Archevêque J, Malo JL. - Exposure to a sensitizing occupational agent can cause a long-lasting increase in bronchial responsiveness to histamine in the absence of $\mathrm{s}$ ignificant changes in airway calibre. $J$ Allergy Clin Immunol 1986; 78: 1185-1189.

201. Malo JL, Ghezzo H, L'Archevêque J, Cartier A. - Late asthmatic reactions to occupational sensitizing agents: frequency of changes in non-specific bronchial responsiveness and of response to inhaled beta-2-adrenergic agent. $J$ Allergy Clin Immunol 1990; 85: 834-842.

202. Carroll K, Secombe C, Pepys J. - Asthma due to nonoccupational exposure to toluene (tolyne) diisocyanate. Clin Allergy 1976; 6: 99-104.

203. Butcher B, O'Nell C, Reed M, Salvaggio J, Weill H. Development and loss of toluene diisocyanate reactivity: immunologic, pharmacologic, and provocative challenge studies. $J$ Allergy Clin Immunol 1982; 70: 321-325.

204. Polosa R, Hólgate ST, Church MK. - Adenosine as a pro-inflammatory mediator in asthma. Pulm Pharmacol 1989; 2: 21-26.

205. Phillips GD, Holgate ST. - The effect of oral terfenadine alone and in combination with flurbiprofen on the bronchoconstrictor response to inhaled adenosine 5'-monophosphate in nonatopic asthma. Am Rev Respir Dis 1989; 139: 463469.

206. Phillips GD, Ng WH, Church MK, Holgate ST. - The response of plasma histamine to bronchoprovocation with methacholine, adenosine 5'-monophosphate, and allergen in atopic nonasthmatic subjects. Am Rev Respir Dis 1990; 141: 9-13.

207. Lewis RA, Austen KF, Soberman RJ. - Leukotrienes and other products of the 5-lipoxygenase pathway. Biochemistry and relation to pathobiology in human diseases. $N$ Engl $J$ Med 1990; 323: 645-655.

208. Arm JP, O'Hickey SP, Hawksworth RJ, Fong CY, Crea AEG, Spur BW, Lee TH. - Asthmatic airways have a disproportionate hyperresponsiveness to LTE4, as compared with normal airways, but not to LTC4, LTD4, methacholine, and histamine. Am Rev Respir Dis 1990; 142: 1112-1118. 209. O'Hickey SP, Hawkworth RJ, Fong CY, Arm JP, Spur BW, Lee TH. - Leukotriene C4, $\mathrm{D}_{4}$ and $\mathrm{E}_{4}$ enhance histamine responsiveness in asthmatic airways. Am Rev Respir Dis 1991; 144: 1053-1057.

210. Bel EH, van der Veen H, Kramps JA, Dijkman JH, Sterk PJ. - Maximal airway narrowing to inhaled leukotriene D4 in normal subjects. Comparison and interaction with methacholine. Am Rev Respir Dis 1987; 136: 979-984.

211. Frölund L, Madsen F, Nielsen J. - Reproducibility of leukotriene D4 inhalation challenge in asthmatics. Allergy 1991; 46: 355-361.

212. Chung KF. - Platelet-activating factor in inflammation and pulmonary disorders. Clin Sci 1992; 83: 127-138.

213. Cuss FM, Dixon CMS, Bames PJ. - Effects of inhaled platelet-activating factor on pulmonary function and bronchial responsiveness in man. Lancet 1986; ii: 189-192.

214. Lai CKW, Holgate ST. - Does inhaled PAF cause airway hyperresponsiveness? Clin Exp Allergy 1990; 20: 449-452. 215. Bames PJ. - Bradykinin and asthma. Thorax 1992; 47: 979-983.

216. Fuller RW, Dixon CMS, Cuss FMC, Barnes PJ. Bradykinin-induced bronchoconstriction in humans. Mode of action. Am Rev Respir Dis 1987; 135: 176-180.

217. Djukanovic R, Polosa R, Holgate ST. - The effect of bronchial allergen challenge on methacholine $(\mathrm{MCH})$ and bradykinin (BK) airway responsiveness. Eur Respir J 1991; 4 (suppl 14): 340 S.

218. Dixon CMS, Fuller RW, Bames PJ. - Effect of nedocromil sodium on sulphur dioxide induced bronchoconstriction. Thorax 1987; 42: 462-465. 
219. Nichol GM, Nix A, Chung KF, Barnes PJ. - Characterisation of bronchoconstrictor response to sodium metabisulphite aerosol in atopic subjects with and without asthma. Thorax 1989; 44: 1009-1014.

220. Wright W, Zhang YG, Salome CM, Woolcock AJ. Effect on inhaled preservatives on asthmatic subjects. I. Sodium metabisulfite. Am Rev Respir Dis 1990; 141: 1400-1404.

221. Woolcock AJ, Anderson SD, Peat JK, Du Toit JI, Guang Zhang Y, Smith CM, Salome CM. - Characteristics of bronchial hyperresponsiveness in chronic obstructive pulmonary disease and in asthma. Am Rev Respir Dis 1991; 143: 14381443.

222. Solway J, Leff AR. - Sensory neuropeptides and airway function. J Appl Physiol 1991; 71: 2077-2087.

223. Joos G, Pauwels R, van der Straeten M. - Effect of inhaled substance $P$ and neurokinin $A$ on the airways of normal and asthmatic subjects. Thorax 1987; 42: 779-783.

224. Cheung D, Bel EH, den Hartigh J, Dijkman JH, Sterk PJ. - The effect of an inhaled neutral endopeptidase inhibitor, thiorphan, on airway responsiveness to neurokinin A in normal humans in vivo. Am Rev Respir Dis 1992; 145: 1275-1280. 225. Okayama M, Yafuso N, Nogami H, Lin Y-N, Horio S, Hida W, Inoue H, Takishima T. - A new method of inhalation challenge with propranolol: comparison with methacholine-induced bronchoconstriction and role of vagal nerve activity. $J$ Allergy Clin Immunol 1987; 80: 291-299.

226. Gerritsen J, Koëter GH, van der Weele LT, Knol K. Propranolol inhalation challenge in relation to histamine response in children with asthma. Thorax 1988; 43: 451-453. 227. Sterk PJ, Bel EH. - The shape of the dose-response curve to inhaled bronchoconstrictor agents in asthma and in chronic obstructive pulmonary disease. Am Rev Respir Dis 1991; 143: 1433-1437.

228. Cockcroft DW, Berscheid BA. - The slope of the doseresponse curve: usefulness in assessing bronchial responses to inhaled histamine. Thorax 1983: 38: 55-61.

229. Woolcock AJ, Salome CM, Yan K. - The shape of the dose-response curve to histamine in asthmatic and normal subjects. Am Rev Respir Dis 1984; 130:71-75.

230. James A, Lougheed D, Pearce-Pinto G, Ryan G, Musk B. - Maximal airway narrowing in a general population. Am Rev Respir Dis 1992; 146: 895-899.

231. Bel EH, Zwinderman AH, Timmers MC, Dijkman JH, Sterk PJ. - The protective effect of a $\beta_{2}$ agonist against excessive airway narrowing in response to bronchoconstrictor stimuli in asthma and chronic obstructive lung disease. Thorax 1991: 46: 9-14.

232. O'Connor G, Sparrow D, Taylor D, Segal M, Weiss S. - Analysis of dose-response curves to methacholine. An approach suitable for population studies. Am Rev Respir Dis 1987; 136: 1412-1417.

233. Abramson MJ, Saunders NA, Hensley MJ. - Analysis of bronchial reactivity in epidemiological studies. Thorax 1990; 45: 924-929.

234. Peat JK, Salome CM, Berry G, Woolcock AJ. - Relation of dose-response slope to respiratory symptoms in a population of Australian schoolchildren. Am Rev Respir Dis 1991; 144: 663-667.

235. Peat JK, Salome CM, Berry G, Woolcock AJ. - Relation of dose-response slope to respiratory symptoms and lung function in a population of adults living in Busselton, Western Australia. Am Rev Respir Dis 1992; 146: 860-865.

236. Altman DC, Bland JM. - Measurement in medicine. The analysis of method comparison studies. The Statistician 1983; 32: 307-317.

237. Streiner DL, Norman GR. - Health measurement scales. Oxford Univ Press 1989; pp 79-96.
238. Chinn S. - Repeatability and method comparison. Thorax 1991; 46: 454-456.

239. Chinn S. - Scale, parametric methods, and transformations. Thorax 1991; 46: 536-538.

240. Knox AJ, Wisniewski A, Cooper S, Tattersfield AE. A comparison of the Yan and a dosimeter method for methacholine challenge in experienced and inexperienced subjects. Eur Respir J 1991; 4: 497-502.

241. Balzano G, Carri ID, Gallo C, Cocco G, Melillo G. Intrasubject between-day variability of $\mathrm{PD}_{20}$ methacholine assessed by a dosimeter inhalation test. Chest 1989; $44: 474$ 479.

242. Chinn S, Burney PGJ, Britton JR, Tattersfield AE, Higgins BG. - Measures of response to bronchial challenge for use in epidemiological studies: a comparison. Eur Respir $J$ 1992; 5 (suppl 15): 493 S.

243. De Pee S, Timmers MC, Hermans J, Duiverman EJ, Sterk PJ. - Comparison of maximal airway narrowing to methacholine between children and adults. Eur Respir J 1991; 4: 421428.

244. Anderson SD, Schoeffel RE. - Standardization of exercise testing in the asthmatic patient: a challenge in itself. In: Airway Responsiveness. Ed. F.E. Hargreave and A.J. Woolcock. Astra Pharmaceuticals Canada Ltd, ISBN 0-920163-02-5: 5159.

245. Kopferschmitt-Kubler MC, Bigot H, Paili G. - Allergen bronchial challenge tests: variability and reproducibility of the early response. J Allergy 1987; 80: 730-740.

246. Wong CS, Wahedna I, Pavord ID. Tattersfield AE. Repeatability of the early response to allergen in subjects with mild atopic asthma. Thorax 1992; 47: 231P.

247. Durham SR. - Late asthmatic responses. Respir Med 1990; 84: 263-268.

248. Twentyman O, Holgate ST. - Reproducibility of the late asthmatic reaction: comparison with histamine bronchoprovocation test. Thorax 1989; 44: 867P.

249. Bel EH, Timmers MC, Dijkman JH, Stahl EG, Sterk PJ. - The effect of an inhaled leukotriene antagonist, L-648,051, on early and late asthmatic reactions and subsequent increase in airway responsiveness in man. J Allergy Clin Immunol 1990; 85: $1067-1075$.

250. Benson MK. Bronchial hyperreactivity. Br J Dis Chest 1975; 69: 227-239.

251. Rijcken B, Schouten JP, Weiss ST, Speizer FE, van der Lende R. - The relationship between airway responsiveness to histamine and pulmonary function level in a random population sample. Am Rev Respir Dis 1988; 137: 826-832.

252. Ryan G, Latimer KM, Dolovich J, Hargreave FE. Bronchial responsiveness to histamine: relationship to diurnal variation of peak flow rate, improvement after bronchodilator, and airway calibre. Thorax 1982; 37: 423-429.

253. Josephs LK, Gregg I, Mullee MA, Campbell MJ, Holgate ST. - A longitudinal study of baseline FEV Fnd $_{1}$ bronchial responsiveness in patient with asthma. Eur Respir J 1992; 5: $32-39$.

254. Dirksen A, Madsen F, Engel T, Frölund L, Heinig JH, Mosbeck H. - Airway calibre as a confounder interpreting bronchial responsiveness in asthma. Thorax 1992; 47: 702706.

255. Postma DS, de Vries K, Koëter GH, Sluiter HJ. Independent influence of reversibility of air-flow obstruction and nonspecific hyperreactivity on the long-term course of lung function in chronic air-flow obstruction. Am Rev Respir Dis 1986; 134: 276-280.

256. Toelle BG, Peat JK, Salome CM, Mellis CM, Woolcock AJ. - Toward a definition of asthma for epidemiology. Am Rev Respir Dis 1992; 146: 633-637. 
257. Tattersfield AE. - Effect of beta-agonists and anticholinergic drugs on bronchial reactivity. Am Rev Respir Dis 1987; 4: S64-S67.

258. Van Essen-Zandvliet EEM, Kerrebijn KF. - The effect of anti-asthma drugs on bronchial hyperresponsiveness. Immunol Allergy Clin North Am 1990; 10: 483-501.

259. Postma DS. Inhaled therapy in COPD: what are the benefits? Respir Med 1991; 85: 447-449.

260. Chung KF. - Long-term corticosteroid therapy in chronic airways obstruction. Eur Respir J 1992; 5: 913-914.

261. Groot CAR, Lammers J-WJ, Molema J, Festen J, van Herwaarden CLA. - Effects of inhaled beclomethasone and nedocromil sodium on bronchial hyperresponsiveness to histamine and distilled water. Eur Respir J 1992; 5: 10751082.

262. Groot CAR, Lammers J-WJ, Festen J, van Herwaarden CLA. - Correlations of symptom scores and $\beta_{2}$-agonist use with bronchial hyperresponsiveness to histamine and distilled water and perception of dyspnoea during histamine and distilled water. Eur Respir J 1992; 5 (suppl 15): 451S.

263. O'Byme PM, Ramsdale EH, Hargreave FE. - Isocapnic hyperventilation for measuring airway hyperresponsiveness in asthma and in chronic obstructive pulmonary disease. Am Rev Respir Dis 1991; 143: 1444-1445.

264. O'Byme PM. - Allergen-induced airway hyperresponsiveness. J Allergy Clin Immunol 1988; 81: 119-127. 